\title{
Viscerotropic disease: Case definition and guidelines for collection, analysis, and presentation of immunization safety data
}

\author{
Mark D. Gershman a,*, J. Erin Staples ${ }^{\text {b }}$, Adwoa D. Bentsi-Enchillc, J. Gabrielle Breugelmans ${ }^{\text {d }}$, \\ Glacus S. Brito ${ }^{\mathrm{e}}$, Luiz Antonio Bastos Camacho ${ }^{\mathrm{f}}$, Pascale Cottin ${ }^{\mathrm{g}}$, Cristina Domingo ${ }^{\mathrm{h}}$, Anna Durbin ${ }^{\mathrm{i}}$, \\ Joaquim Gascon ${ }^{\mathrm{j}}$, Fouzia Guenaneche ${ }^{\mathrm{k}, 1}$, Edward B. Hayes $^{\mathrm{j}}$, Zsuzsanna Jelenik $^{1}$, Alena Khromava ${ }^{\mathrm{m}}$, \\ Reinaldo de Menezes Martins ${ }^{\mathrm{n}}$, Mario Masana Wilson ${ }^{\mathrm{o}, 2}$, Nathalie Massy ${ }^{\mathrm{p}}$, Abdulsalami Nasidi ${ }^{\mathrm{q}}$, \\ Matthias Niedrig ${ }^{\mathrm{h}}$, Adam Sherwat ${ }^{\mathrm{r}, 3}$, Theodore Tsai ${ }^{\mathrm{s}}$, Anna Vilella ${ }^{\mathrm{j}}$, Mary Elizabeth Wilson ${ }^{\mathrm{t}}$, \\ Katrin S. Kohl ${ }^{\mathrm{a}}$, The Brighton Collaboration Viscerotropic Disease Working Group
}

a Division of Global Migration and Quarantine, National Center for Emerging and Zoonotic Infectious Diseases, Centers for Disease Control and Prevention, 1600 Clifton Road, N.E., MS-E03, Atlanta, GA 30333, USA

${ }^{\mathrm{b}}$ Division of Vector-Borne Diseases, National Center for Emerging and Zoonotic Infectious Diseases, Centers for Disease Control and Prevention, 3150 Rampart Road, Mailstop P-02, Fort Collins, CO 80521, USA

${ }^{\mathrm{c}}$ Department of Immunization, Vaccines, and Biologicals, World Health Organization, 20 Avenue Appia, 1211 Geneva 27, Switzerland

d Agence de Médecine Préventive, s/c Institut Pasteur-25-28 rue du Docteur Roux - 75724, Paris, Cedex 15, France

e Division of Clinical Immunology and Allergy, Hospital das Clinicas FMUSP, Prédio dos Ambulatórios, Av. Dr. Eneas de Carvalho Aguiar, 155, 05403.000 São Paulo, SP, Brazil

${ }^{\mathrm{f}}$ Escola Nacional de Saúde Pública, Fundação Oswaldo Cruz, Rua Leopoldo Bulhões, 1480, Sala 820, Manguinhos, Rio de Janeiro, RJ 21041-210, Brazil

g Global Pharmacovigilance \& Epidemiology, Sanofipasteur, 2 avenue du Pont Pasteur, 69007 Lyon, France

${ }^{\text {h }}$ Robert Koch Institute, Nordufer 20, 13353 Berlin, Germany

i Center for Immunization Research, Department of International Health, Johns Hopkins Bloomberg School of Public Health, 624N, Broadway, Baltimore, MD 21205, USA

j Barcelona Centre for International Health Research (CRESIB, Hospital Clínic-Universitat de Barcelona), Villarroel, 170, 08036, Barcelona, Spain

${ }^{\mathrm{k}}$ Division of Safety Monitoring and Risk Management for Pediatric and Travel Vaccines, sanofipasteur MSD, 8 rue Jonas Salk, 69367 Lyon, Cedex 07, France

${ }^{1}$ International Traveller's Health and Vaccination Centre, National Centre of Epidemiology, 1097 Budapest, Gyáli. u. 2-6, Hungary

${ }^{m}$ Global Pharmacovigilance and Epidemiology Department, Sanofipasteur Ltd., 1755 Steeles Ave West, Toronto, ON M2R 3T4, Canada

${ }^{n}$ Bio-Manguinhos/Fiocruz, Av. Brasil 4365, Manguinhos, 21040-900 Rio de Janeiro, RJ, Brazil

${ }^{\circ}$ Epidemiology Direction, Ministry of Health, Av. 51 № 1120, La Plata, Buenos Aires Province, Argentina

P Pharmacovigilance Regional Center of Upper-Normandy, Rouen University Hospital, 1 rue de Germont 76031, Rouen, Cedex, France

${ }^{q}$ Federal Ministry of Health, Federal Secretariat, Shehu Shagari Way, Maitama, Abuja, Nigeria

${ }^{\mathrm{r}}$ Division of AIDS, National Institute of Allergy and Infectious Diseases, National Institutes of Health, 6700 B Rockledge Drive, Bethesda, MD 20892, USA

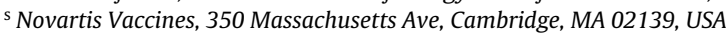

${ }^{t}$ Department of Global Health and Population, Harvard School of Public Health, 655 Huntington Ave, Boston, MA 02115, USA

\section{A R T I C L E I N F O}

Article history:

Received 13 April 2012

Accepted 19 April 2012

Available online 4 May 2012

\section{Keywords:}

Viscerotropic disease

\footnotetext{
is Disclaimer: The findings, opinions and assertions contained in this consensus document are those of the individual scientific professional members of the working

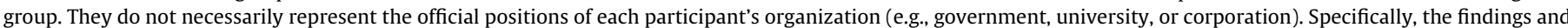

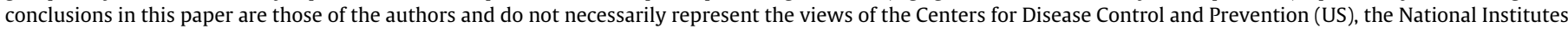
of Health (US), or the World Health Organization.

* Corresponding author at: Centers for Disease Control and Prevention, 1600 Clifton Road, N.E., MS-E03, Atlanta, GA 30333, USA. Tel.: +1 404 639 7390;

fax: +1 4046394441

E-mail address: contact@brightoncollaboration.org (M.D. Gershman).

1 Present address: 47 Rue du Lieutenant Colonel Girard, 69007 Lyon, France.

2 Present address: Health Surveillance, Disease Prevention and Control, Pan American Health Organization, Calle Víctor Sanjines 2678, Edificio Torre Barcelona, Zona Sopocachi, La Paz, Bolivia.

${ }^{3}$ Present address: Division of Antiviral Products, Office of Antimicrobial Products, Office of New Drugs, Center for Drug Evaluation and Research, Food and Drug Administration, 10903 New Hampshire Ave., Bldg. 22, Silver Spring, MD 20903, USA.
} 


\section{Preamble}

\subsection{Need for developing case definitions and guidelines for} viscerotropic disease as an adverse event following immunization

Viscerotropic disease (VTD) is defined as acute multiple organ system dysfunction that occurs following vaccination. The severity of VTD ranges from relatively mild multisystem disease to severe multiple organ system failure and death. The term VTD was first used shortly after the initial published reports in 2001 of febrile multiple organ system failure following yellow fever (YF) vaccination [1-7]. To date, VTD has been reported only in association with YF vaccine and has been thus referred to as YF vaccine-associated viscerotropic disease (YEL-AVD).

YF vaccine is manufactured from the live attenuated 17D virus substrain. It is considered relatively safe and effective in preventing YF disease, which results from YF virus transmission through the bite of an infected mosquito [8]. YF virus circulates in sub-Saharan Africa and tropical South America, where it causes endemic and intermittently epidemic disease. Most YF disease in these areas is attributable to jungle (sylvatic) or savanna (intermediate) transmission cycles, which occur predominantly in sparsely populated forested areas and rural villages, respectively [8]. To protect vulnerable populations, endemic countries target YF vaccination efforts towards their residents, who reside in both rural and urban settings with varying resources.

YEL-AVD is believed to result from widespread dissemination and replication of live attenuated 17D YF vaccine virus, similar to the natural YF virus. Virologic studies have documented vaccine virus in a number of postmortem tissues obtained from YEL-AVD case patients [1-3,9-14]. The initial symptoms of YEL-AVD are nonspecific, including fever, headache, malaise, myalgia, arthralgia, nausea, vomiting, and diarrhea, and resemble those of the early phase of YF disease. As YEL-AVD progresses, jaundice can appear, along with thrombocytopenia and elevations of hepatic transaminases, total bilirubin, and creatinine. Severe YEL-AVD is characterized by hypotension, hemorrhage, acute renal failure, and acute respiratory failure. Less frequent manifestations include rhabdomyolysis and disseminated intravascular coagulation (DIC). There is no specific therapy for YEL-AVD; treatment is supportive. YEL-AVD is fatal in more than $60 \%$ of reported cases [8], although this rate is probably an overestimate because case confirmation is more likely in fatal cases than nonfatal ones.

As of March 2010, the Brighton Collaboration Viscerotropic Disease Working Group had identified 60 published and unpublished reports of YEL-AVD from Asia, Australia, Europe, and North and

Abbreviations: AEFI, adverse event following immunization; ALT, alanine aminotransferase; AST, aspartate aminotransferase; BP, blood pressure; CDC, Centers for Disease Control and Prevention (US); CPK, creatine phosphokinase; DIC, disseminated intravascular coagulation; FDP, fibrin degradation products; IHC, immunohistochemistry; INR, international normalized ratio; PCR, polymerase chain reaction; PFU, plaque-forming unit; RBC, red blood cell; RNA, ribonucleic acid; ULN upper limit of normal; UNICEF, United Nations Children's Fund; VAERS, Vaccine Adverse Events Reporting System (US); VTD, viscerotropic disease; WHO, World Health Organization; YEL-AVD, yellow fever vaccine-associated viscerotropic disease; YF, yellow fever; YFI, Yellow Fever Initiative; YFWG, Yellow Fever Vaccine Safety Working Group.
South America. A number of suspected YEL-AVD cases have been detected in Africa through enhanced surveillance conducted in conjunction with mass YF vaccination campaigns, but information on these cases is limited. YEL-AVD cases have been reported following vaccination with different attenuated 17D YF vaccine virus substrains that have been produced by several manufacturers [8]. YEL-AVD appears to occur only after a person's first YF vaccination; there are no reports of YEL-AVD following booster doses of YF vaccine. The median time from vaccination until symptom onset is 3 days (range: $1-8$ days). The median time from YF vaccination until death is 10 days (range: 7-30 days) [8].

Data from US and European travelers indicate that YEL-AVD occurs at a frequency of $0.3-0.4$ per 100,000 YF vaccine doses distributed [15-17]. An analysis of fatal cases in mass vaccination campaigns in Brazil yielded a lower risk estimate of 0.0043-0.2131 per 100,000 doses administered [9]. However, more recent risk estimates reported from Brazil, using data from vaccination campaigns in 2008-2009, are similar to those reported from the United States and Europe [18]. In 2007, an unprecedented cluster of five cases of YEL-AVD, four of which were fatal, occurred following the use of a single lot of YF vaccine administered as part of a vaccination campaign in a nonendemic area of Peru. The overall incidence of YEL-AVD in this campaign was 7.9 per 100,000 doses administered, and the lot-specific incidence was 11.7 per 100,000 doses [12]. A thorough investigation found no clear explanation for the substantially higher incidence of YEL-AVD in this campaign or with this specific vaccine lot.

Advanced age has been identified as a risk factor for YEL-AVD. Two analyses of YEL-AVD reports to the Vaccine Adverse Events Reporting System (VAERS) in the United States yielded a reporting rate of 1.4-1.8 cases of YEL-AVD per 100,000 doses for persons aged $\geq 60$ years $[15,16]$. This rate is several times higher than the overall reporting rate of $0.3-0.4$ per 100,000 doses. In addition, a history of thymus disease or thymectomy is considered a risk factor, based on the observation that four of the first 23 reported cases of YELAVD had a history of thymectomy for either benign or malignant thymoma [19].

In 2002, an informal Yellow Fever Vaccine Safety Working Group (YFWG) was convened to discuss cases of YEL-AVD. The YFWG included staff of the US Centers for Disease Control and Prevention (CDC), World Health Organization (WHO), various US academic institutions, the US Food and Drug Administration, the US Department of Defense, and vaccine manufacturers. This working group reviewed reports to VAERS of serious adverse events following YF vaccination and developed a case definition for YEL-AVD. This case definition, published in original [8] and in modified form [20], provided the basis for case definitions subsequently used in the investigation of suspected YEL-AVD cases in Brazil and Peru [12], by a major YF vaccine manufacturer, and by WHO $[21,22]$. However, this case definition was never subjected to a formal peer review process and was never adopted as an international standard.

The original YFWG case definition has limitations. It combines case-finding criteria, useful to search surveillance systems for reports of potential cases of YEL-AVD, with clinical and laboratory abnormalities used for case confirmation. To be classified as YEL-AVD, a case must meet the case-finding criteria (fever and at least one other symptom from a list of nonspecific symptoms) and 
have at least one of eleven listed clinicopathologic manifestations that indicate organ system dysfunction. Given that YEL-AVD is recognized to be a syndrome of multiple organ system dysfunction (or failure), the case definition requirement for only one clinical or laboratory abnormality contributes to a lack of diagnostic specificity. The original YEL-AVD case definition includes a YF vaccine causality assessment, without explanation of the rationale for the selected causality criteria. Moreover, the case definition and causality assessment are linked together without provision for broader application of the YEL-AVD case definition to similar reactions that might occur with other vaccines.

Since 2007, the Yellow Fever Initiative (YFI), a collaboration of WHO and UNICEF, has assisted countries in West Africa to plan and conduct mass vaccination campaigns against YF. During 2007 through 2010, the YFI program vaccinated 57 million people in 10 countries [23]. In addition, the YFI has assisted 22 African countries in the successful introduction of YF vaccine into their routine childhood immunization programs and has been involved in expanding routine childhood YF vaccination coverage in the Americas. The YFI plan for these mass vaccination campaigns includes protocols for investigating adverse events following immunization (AEFI) [21,22]. However, the lack of a globally accepted case definition for YEL-AVD, which would be applicable to resource-poor settings, was identified as an impediment to accurate and standardized AEFI case classification. Consequently, the WHO recommended to the Brighton Collaboration (https://brightoncollaboration.org/public) leadership that a Brighton Collaboration working group be formed to develop a standard case definition for VTD.

To this end, the Brighton Collaboration initiated a working group in 2008 to develop a standardized case definition and guidelines for the collection, analysis, and presentation of data for VTD as an AEFI. The case definition and guidelines are intended to be applicable in diverse geographic, administrative, and cultural regions, regardless of differences in the availability of resources, including laboratory diagnostic capabilities, and access to health care. Standardized application of this definition with its guidelines will enable data comparability and hopefully lead to a better understanding of VTD. Previously published WHO guidance regarding the case definition and data collection for YEL-AVD, as well as the case definition developed by the YFWG, preceded the development of these guidelines [8,20-22]. The more recent and more detailed Brighton Collaboration case definition and guidelines presented here are preferred.

\subsection{Methods for the development of the case definition and guidelines for VTD as an AEFI}

Following the process described in the Brighton Collaboration overview paper [24], the Brighton Collaboration VTD WG (the WG) comprised 30 members from 10 countries, representing academia, public health, regulatory organizations, and industry. The results of the web-based survey of the VTD case definition, completed by the reference group, with subsequent discussions in the working group, can be viewed at: https:// brightoncollaboration.org/public/resources/surveyfeedback/

VTDcasedefinition.html.

To guide development of the case definition and guidelines, a systematic literature search identified articles addressing YEL-AVD. Because no specific indexing term for this serious AEFI existed at the time of the literature search, a combination of more general search terms was used, including yellow fever vaccine, immunization, viscerotropic, multiple organ failure, systemic inflammatory response syndrome, disseminated intravascular coagulation, sepsis, liver dysfunction, kidney dysfunction, and adverse event. Sources included the Cochrane Library, MEDLINE (1950-July week 3, 2008) and Embase (1980-week 30, 2008). Nine hundred articles were initially identified. Based on a review of the title and abstract, 21 articles (20 in English and 1 in Chinese) were selected for further evaluation. These publications were mainly case reports of one or more cases of YEL-AVD. Several were reports of molecular analyses of YF vaccine strain virus isolates from patients who had developed YEL-AVD and included limited clinical case report information. Although several of the publications referred to using the YFWG case definition for YEL-AVD, none listed the details of the case definition. Selected published articles and unpublished case reports available at the CDC and WHO were summarized in an inventory to include information on the clinical signs and symptoms of 36 cases of YEL-AVD. The WG reviewed this inventory and designated case definition criteria based on the most frequently reported clinicopathologic manifestations.

An additional literature search of MEDLINE was performed by the WG, specifically to identify reports of multiple organ system disease following immunization with other vaccines. Search terms used were multiple organ failure and vaccines; multiple organ failure and measles mumps rubella or varicella or herpes zoster or polio or rotavirus or influenza or Bacille Calmette-Guérin (BCG) or Ty21a typhoid vaccine. Published reports of multiple organ system failure were identified following administration of varicella vaccine (2 reports), oral polio vaccine (1 report), and BCG vaccine (numerous reports). The majority of articles retrieved from the multiple organ failure AND BCG search were reports of multiple organ system failure and sepsis following intravesical administration of BCG used to treat bladder cancer in adults. However, there were a few reports of disseminated BCG infection in infants after BCG immunization. These reports were retrieved and reviewed. Additionally, the 900 abstracts from the original literature search were re-reviewed for any reports of multiple organ system failure associated with vaccines other than YF vaccine. No such reports were identified by this last strategy.

\subsection{Rationale for selected decisions about the case definition for VTD as an AEFI}

\subsubsection{The term viscerotropic disease}

The WG chose to use the term "viscerotropic disease," rather than "multiple organ system failure" because it is the term currently used in the vaccine safety literature to describe this AEFI, and we felt it more accurately describes both the pathogenesis and the full spectrum of disease severity. The WG defined "viscerotropic disease" rather than "yellow fever vaccine-associated viscerotropic disease" because we consider it important to first confirm the clinical entity itself at a given level of diagnostic certainty and afterward to assess its causal relation to vaccination in a separate step using a causality algorithm. Although the term VTD has thus far been applied only to the syndrome of multiple organ system failure following YF vaccination, other cases of multiple organ system failure associated with varicella [25,26], poliovirus [27], and BCG [28] vaccines were found through the literature search. These AEFIs were not entirely similar to those seen with YF vaccine (e.g., different age groups or time course). However, overlapping clinical features suggest that the VTD case definition would have utility for multiple vaccines. Additionally, having a stand-alone VTD case definition exclusive of any assessment for YF vaccine causality will allow for its potential future use following immunization with other, not yet licensed vaccines. An example of the latter is the live chimeric vaccines in development that are based on the 17D YF vaccine virus backbone. Although clinical trials to date have shown these vaccines to have excellent safety profiles [29], the possibility cannot be eliminated that future, post-licensing experience might demonstrate the rare occurrence of VTD. 


\subsubsection{Structure of the VTD case definition}

The Brighton Collaboration VTD case definition has been constructed in accordance with the general format for Brighton Collaboration case definitions, with three levels of diagnostic certainty. Level 1 has the highest degree of specificity and the lowest degree of sensitivity. Moving from Level 1 to Level 3 there is a stepwise increase of sensitivity with a corresponding decrease in specificity. The case definition levels differ in diagnostic certainty, not in clinical severity of VTD. Similarly, levels of diagnostic certainty do not reflect causal association with a given vaccine.

The WG designated major and minor criteria for each clinicopathologic manifestation of VTD, to be used in various combinations to meet the requirements of each level of the case definition. The distinction between corresponding major and minor criteria is based on diagnostic certainty, not on clinical severity, a relationship which is consistent with that between the three levels of the case definition. The major and minor criteria for each clinicopathologic manifestation were particularly selected to facilitate application of the case definition in diverse clinical settings with varying diagnostic resources. For example, elevated serum total bilirubin indicates liver dysfunction to a higher degree of diagnostic certainty than jaundice, which is observer-dependent and may have causes other than liver dysfunction. Consequently, elevation of total bilirubin is a major criterion and jaundice is a minor criterion for the clinicopathologic manifestation of liver dysfunction.

The WG recognized that categorizing individual clinical and laboratory abnormalities as discrete case definition criteria is an artificial construct. VTD involves multiple organ systems and physiologic processes that are dynamically interconnected in the body's normal functioning, as well as in pathophysiologic states. Abnormal laboratory results primarily identified with one system might actually result from the dysfunction of several organ systems. Nevertheless, the ability to easily apply the case definition to a complex clinical event requires that the clinicopathologic abnormalities comprising the case definition be categorized discretely.

The WG decided to exclude any symptoms from its VTD case definition because symptoms are too general and nonspecific to differentiate the multiple organ system syndrome of VTD from other clinical events. Although symptoms might be useful for case finding, they do not contribute substantially to any degree of diagnostic certainty about VTD. Fever deserves special mention because it is both a symptom and a physical sign. Fever as a symptom was excluded for the aforementioned reasons; fever as a sign was excluded from the case definition because, although it is objectively measured, it is not a specific indicator of organ dysfunction.

\subsubsection{Decisions about specific major and minor criteria}

Because the previous YFWG case definition for YEL-AVD [8] has been widely used in the assessment of VTD, this WG deliberated in great detail any changes made. For example, although tachycardia and bradycardia are both included in the previous case definition of YEL-AVD, the WG decided to exclude these from the Brighton Collaboration VTD case definition. The WG felt that while tachycardia might be generally indicative of severe illness, it is too nonspecific a clinical sign to add diagnostic certainty. Faget's sign, which is characteristic of YF, is a bradycardia relative to the expected heart rate increase accompanying elevated body temperature [30]. However, it does not appear to be a common feature of YEL-AVD, as it was noted in only one of 31 cases in which symptoms were reported.

The previous YFWG case definition of YEL-AVD defines thrombocytopenia as platelet count less than $100,000 / \mathrm{mm}^{3}$, as does the case definition of thrombocytopenia as an adverse drug reaction developed by an expert group convened by the Council for International Organizations of Medical Sciences (CIOMS) [31]. This WG chose the same threshold, since $65 \%$ of YEL-AVD cases in the inventory had a platelet count below this level; it unequivocally reflects an abnormally low platelet count. The WG chose to use the term "platelet disorder" rather than "thrombocytopenia" to label the major criterion of a low platelet count, to avoid confusion with the existing Brighton Collaboration general case definition of thrombocytopenia, defined as a platelet count less than $150,000 / \mathrm{mm}^{3}$ [32].

Rhabdomyolysis is a less common manifestation of YEL-AVD that has been reported with severe cases. The previous YFWG case definition of YEL-AVD defines rhabdomyolysis as a measured serum creatine phosphokinase (CPK) level of greater than five times normal. Published articles on rhabdomyolysis indicate that an elevation of CPK is the most sensitive indicator of rhabdomyolysis $[33,34]$. Although there is no established diagnostic cut-off level of CPK for the diagnosis of rhabdomyolysis, five times the upper limit of normal is commonly used in clinical practice [33-35]. The consensus of the WG was to use the commonly applied threshold of CPK elevation for the major criterion of rhabdomyolysis. The WG chose as the corresponding minor criterion for rhabdomyolysis a positive urine dipstick test for blood with a negative urine microscopic examination for red blood cells (RBCs). If no RBCs are detected by urine microscopy, a positive dipstick test for blood can usually be attributed to myoglobinuria [36-38]. This is the only minor criterion selected for the VTD case definition that involves laboratory testing, but the required laboratory equipment is basic and should be available in many clinics in resource-poor settings. Although myoglobinuria has been described to impart a tea or cola color to urine, bilirubinuria can produce a similar color [39]. Since bilirubinemia is reported more commonly than rhabdomyolysis in cases of YEL-AVD, bilirubinuria likely occurs more frequently than myoglobinuria. Hence, urine discoloration is too nonspecific to be used as the minor criterion for rhabdomyolysis.

Disseminated intravascular coagulation (DIC) also has been reported with severe cases of YEL-AVD. However, abnormalities of a single laboratory coagulation test were reported more frequently in the inventory of YEL-AVD case reports than DIC or elevated fibrin degradation products (FDP). The WG recognized that coagulopathy may manifest on a spectrum ranging from mild elevation of the international normalized ratio (INR), prothrombin time (PT), or activated partial thromboplastin time (APTT), to the detection of FDP and presence of hemorrhage suggestive of DIC. Consequently, using the broader category of coagulopathy rather than DIC as a major criterion adds sensitivity to the VTD case definition. In clinical practice, DIC is not defined by any one laboratory test, but rather is a clinical diagnosis based on abnormalities of multiple laboratory tests of coagulation, including FDP and platelets, along with clinical signs. The WG decided to include laboratory evidence of coagulopathy or clinically evident hemorrhage from more than one body site as elements of the major coagulopathy criterion; the latter was felt to be more consistent with DIC than hemorrhage from a single body site. The corresponding minor criterion was designated as clinically evident hemorrhage from one body site.

The WG excluded hematuria as one of the criteria for coagulopathy because it is prevalent to a significant degree in the general population, especially in Africa. Studies in localized populations of several West African countries have demonstrated an overall prevalence of Schistosoma haematobium infection in the range of $55 \%-65 \%[40,41]$. Among these infected persons, microhematuria prevalence ranged from $36 \%$ to $76 \%$, depending on age and intensity of infection. The prevalence of microhematuria in uninfected individuals was $17 \%$ in one study in Africa [40]. This finding is consistent with studies in other settings that have reported a microhematuria prevalence of up to $30 \%$ in apparently healthy people $[42,43]$. Furthermore, approximately one in three persons in West Africa carry the sickle cell trait, for which the most frequent complication is hematuria, both microscopic and macroscopic [44]. Given the relatively high background prevalence of hematuria from 
various causes, hematuria is too nonspecific to be used as an indicator of coagulopathy for the VTD case definition.

\subsubsection{Timing post-immunization}

Because the case definition defines a clinical entity without inference of a causal relation to a given vaccine exposure, the time interval between immunization and onset of the VTD cannot be part of the definition. Generally, the WG recommends surveillance for signs of VTD for 30 days following vaccination. This time period will facilitate detection of VTD cases in resource-poor settings in which a case might be suspected and reported only after a patient's death. For YEL-AVD, the reported time interval between vaccination and symptom onset has been 1-8 days [8]. One reported case involved an unclear time to symptom onset following YF vaccination, with the most conservative interpretation of the available clinical information being 18 days [12]. The evidence suggests that this patient was immunosuppressed prior to vaccination or developed immunosuppression as a result of medication prescribed for initial symptoms following vaccination. The time interval between vaccination and death for reports of YEL-AVD is 7-30 days $[2,12]$. The recommended 30-day surveillance period for VTD allows for potential variation in time interval to symptom onset that might occur in the future in association with other live or chimeric vaccines. Finally, 30 days is commonly used as a surveillance period for collecting reports of adverse events following vaccination.

\subsubsection{YF vaccine causality}

The case definition itself is independent from any assessment of causality. However, because of the clear association of VTD with YF vaccine, the WG decided to create a separate, unlinked algorithm for YF vaccine causality, to be included with this case definition and guidelines (see Appendix A). A causality assessment previously had been part of the YFWG case definition. Unlinking the revised causality algorithm from the VTD case definition will allow the Brighton Collaboration VTD case definition to be applicable to any vaccine. In addition, the causality assessment will help differentiate VTD caused by the vaccine from disease manifestations of wild type YF in the setting of vaccination campaigns undertaken in areas where wild type YF is endemic and/or epidemic.

\subsubsection{Standardizing the use of the case definition}

Recognizing the many variables and uncertainties affecting both the definition and the diagnosis of VTD, the WG has attempted to establish useful and practical guidelines for standardizing the collection, analysis, and presentation of data on VTD in the setting of pre- and post-licensure clinical trials, surveillance, and retrospective epidemiologic studies of vaccine safety. The guidelines are not intended to establish criteria for management of ill patients. As they represent a minimum standard, additional data may be collected, analyzed, and presented as deemed necessary by the investigators. This flexibility is particularly relevant for surveillance of VTD as a potential AEFI with new vaccines against chronic diseases (e.g., diabetes mellitus, rheumatoid arthritis) and therapeutic vaccines (e.g., tumor vaccines), as well as genetically engineered vaccines, mucosal vaccines, or vaccines with slow-release delivery systems, which may require different standards.

Similar to all Brighton Collaboration case definitions and guidelines, regular review of the definition with its guidelines is planned (every 3-5 years) or more often, if needed. The WG encourages users of the case definition to provide feedback on its applicability to the Brighton Collaboration at https://brightoncollaboration.org/public/contact.html.

\section{Case definition of viscerotropic disease $e^{a, b}$}

Level 1 of diagnostic certainty

$\bullet \geq 3$ major criteria ${ }^{c}$

Level 2 of diagnostic certainty

- 2 major criteria $^{c}$

OR

- 1 major criterion and $\geq 2$ minor criteria $^{c}$

Level 3 of diagnostic certainty

$\bullet \geq 3$ minor criteria

OR

- 1 major criterion and 1 minor criterion ${ }^{c}$

a The case definition should be applied when there is temporal association (see Section 1.3.4) with vaccination and no clear alternative diagnosis to account for the symptoms.

${ }^{b}$ Previously published WHO guidance (Refs. [21,22]) regarding the case definition and data collection for YEL-AVD preceded the development of these guidelines; the more recent and more detailed Brighton Collaboration case definition and guidelines presented here are preferred.

${ }^{c}$ Whenever $\geq 1$ major criteria or both a major and minor criteria are used to meet the case definition, they must each represent different organ systems (e.g., hepatic versus renal).

\subsection{Major and minor criteria used in the case definition of} viscerotropic disease

\section{Major criteria}

$\begin{array}{ll}\text { Hepatic: } & \text { Total bilirubin } \geq 1.5 X \text { ULN }^{\mathrm{d}} \\ & {[\geq 1.5 \mathrm{X} \text { patient's baseline value if known] }} \\ & \text { OR } \\ & \text { ALT or AST } \geq 3 \mathrm{X} \mathrm{ULN}^{\mathrm{d}} \\ & {[\geq 3 \mathrm{X} \text { patient's baseline value if known] }} \\ & \text { Creatinine } \geq 1.5 \mathrm{X} \mathrm{ULN}^{\mathrm{d}} \\ \text { Renal: } & {[\geq 1.5 \mathrm{X} \text { patient's baseline value if known] }} \\ \text { Musculoskeletal: } & \text { CPK } \geq 5 \mathrm{X} \text { ULN } \\ \text { Respiratory: } & \text { Oxygen saturation } \leq 88 \% \text { on room air } \\ & \text { OR } \\ & \text { Requirement for mechanical ventilation } \\ \text { Platelet disorder: } & \text { Platelets }<100,000 / \mu L \\ \text { Hypotension: } & \text { Requirement for vasopressor drugs to maintain systolic BP } \\ \text { Coagulopathy: } & \text { INR } \geq 1.5 \text { OR Prothrombin time } \geq 1.5 \mathrm{X} \mathrm{ULN}^{\mathrm{d}} \text { OR Activated } \\ & \text { partial thromboplastin time } \geq 1.5 \mathrm{X} \text { ULN }{ }^{\mathrm{d}} \text { OR elevated FDP } \\ & \text { OR hemorrhage from more than one site }\end{array}$

${ }^{\mathrm{d}} \mathrm{ULN}=$ upper limit of normal for the reference range of normal values reported by the clinical laboratory performing the indicated test.

e FDP = Fibrin degradation products.

f See coagulopathy criterion in Minor criteria table for list of included hemorrhagic sites (hematuria excluded; see Section 1.3.3).

\section{Minor criteria}

$\begin{array}{ll}\text { Hepatic: } & \text { Jaundice } \\ \text { Renal: } & \text { Urine output }<500 \mathrm{~mL} \text { urine } / 24 \mathrm{~h} \text { for adults } \\ & \text { Urine output }<0.5 \mathrm{~mL} / \mathrm{kg} / \mathrm{h} \text { for children }\end{array}$

Musculoskeletal: Positive urine dipstick test for blood with a negative urine microscopy exam for red blood cells

Respiratory: Increasedrespiratory rate for age ${ }^{\mathrm{h}}$

Platelet disorder: Petechiae or purpura present

Hypotension: $\quad$ Systolic BP $<90 \mathrm{mmHg}$ for adults

Systolic BP $<5$ th percentile for age in children $<16$ year

Coagulopathy: Clinically evident hemorrhage (one of the following):

Epistaxis

Hematemesis

Melena

Hematochezia

Hemoptysis

Metrorrhagia or menorrhagia

Gingival hemorrhage

Persistent bleeding from needle puncture sites

${ }^{g}$ Applies to children $<13$ years of age.

${ }^{\text {h}}$ Age-specific thresholds for increased respiratory rate (breaths/min).

6-11 months: $>50$.

$1-5$ years: $>40$.

6 years and older $>20$.

(Modified from: World Health Organization. The management of acute respiratory infections in children: practical guidelines for outpatient care. 1995. Available at: http://whqlibdoc.who.int/publications/1995/9241544775_eng.pdf). 


\section{Complementary guidelines for data collection, analysis, and presentation of viscerotropic disease}

It was the consensus of the Brighton Collaboration VTD WG to recommend the following guidelines to facilitate meaningful and standardized collection, analysis, and presentation of information about VTD. However, implementation of all guidelines might not be possible in all settings. The availability of information may vary, depending upon resources and geographic region and whether the source of information is a prospective clinical trial, post-marketing surveillance, an epidemiologic study, or an individual case report of VTD. Also, as explained in more detail in the Brighton Collaboration overview paper [24], these guidelines have been developed by this WG for guidance only and are not to be considered a mandatory requirement for data collection, analysis, or presentation.

\subsection{Data collection}

These guidelines provide a desirable standard for collection of data on VTD to allow for comparability of data, and are recommended as a supplement to other data that might be collected for any specific study question and investigation setting. The guidelines are not intended to guide the primary reporting of VTD to a surveillance system or study monitor. Investigators developing a data collection tool based on these data collection guidelines also need to refer to the criteria in the case definition, which are not repeated in these guidelines.

Guidelines 2, 4, 5, 11-13, 18-25 below have been developed to address data elements for the collection of adverse event information, as specified in general drug safety guidelines by the International Conference on Harmonization of Technical Requirements for Registration of Pharmaceuticals for Human Use [45] and the form for reporting of drug adverse events by the CIOMS [46]. These data elements include an identifiable reporter and patient, one or more prior immunizations, and a detailed description of the AEFI, in this case, of VTD. The additional guidelines have been developed as guidance for the collection of supplemental information to allow for a more comprehensive understanding of VTD as an AEFI.

\subsubsection{Source of information/reporter}

For all cases and/or all study participants, as appropriate, the following information should be recorded:

1) Date of report.

2) Name and contact information of person reporting ${ }^{4}$ VTD, in accordance with country-specific data protection law.

3) Relationship of the reporter to the vaccine recipient (e.g., immunizer [clinician, nurse], attending physician, family member [indicate relationship], self [vaccine recipient], other).

\subsubsection{Vacinee/control}

For all cases and/or all study participants, as appropriate, the following information should be recorded:

\subsubsection{Demographics.}

4) Case/study participant identifiers (first name initial followed by last name initial) or code (or as otherwise specified in countryspecific data protection laws).

5) Date of birth, age, sex.

6) Country of residence.

\footnotetext{
${ }^{4}$ If the reporting center is different from the vaccinating center, appropriate and timely communication of the adverse event should occur.
}

7) Occupation(s).

8) For infants ( $\leq 12$ months of age): gestational age at birth and birth weight.

\subsubsection{Clinical and immunization history.}

9) Medical history prior to most recent immunization(s), including hospitalizations, surgeries (e.g., thymectomy), underlying diseases/disorders, pre-immunization signs and symptoms.

10) Any medication history prior to, during, and after vaccination, including prescription and nonprescription medication (e.g., herbal or homeopathic medication). These medications should be distinct from those used to treat VTD (refer to Guideline 23). The medication history prior to vaccination should include all medications used in the week prior to vaccination, except for medications with long half-life or long-term effect (e.g., immunoglobulins, blood products, immunosuppressants, and immunomodulators), in which case any use several months prior to vaccination should be recorded. (References on pharmacokinetics for individual medications should be consulted to determine the appropriate length of this time interval).

11) Immunization history (i.e., previous immunizations received more than 30 days before VTD symptom onset, especially vaccines known to cause VTD, such as YF vaccine, and any AEFI ever experienced).

\subsubsection{Details of the immunization}

For all cases and/or all study participants, as appropriate, the following information should be recorded:

12) Date, time, and geographic location of administration (e.g., city or town, state or province, and country) of all immunization(s) given within 30 days prior to onset of VTD symptoms.

13) Description of all vaccine(s) given within 30 days prior to onset of VTD symptoms (name of vaccine, manufacturer, lot number, expiration date, multi- or mono-dose vial, volume [e.g., $0.25 \mathrm{~mL}, 0.5 \mathrm{~mL}$, etc.], dose number if part of a series of immunizations against the same disease(s), and the manufacturer, lot number,and expiration date of any diluent used).

14) Anatomical sites (including left or right side) of all immunizations (e.g., vaccine A in proximal left lateral thigh, vaccine B in left deltoid).

15) Route and method of administration (e.g., intramuscular, intradermal, subcutaneous, oral, intranasal, needle-free [including type and size] or other injection devices).

16) Context of immunization (e.g., routine childhood immunization program, preventive mass immunization campaign, mass immunization campaign for outbreak response, routine adult immunization, domestic travel from nonendemic to endemic area, international travel, occupational risk, military requirements).

\subsubsection{The adverse event}

For all cases at any level of diagnostic certainty and/or all study participants, as appropriate, the following information should be recorded:

17) Criteria fulfilled to meet the case definition and other signs or symptoms indicative of VTD.

18) Detailed clinical description of signs and symptoms of VTD (in particular jaundice, hypoxia, hypotension, oliguria, tachypnea, petechiae or purpura, or hemorrhage). 
19) Date and time of onset, ${ }^{5}$ first observation, ${ }^{6}$ diagnosis, ${ }^{7}$ end of an episode, ${ }^{8}$ and last observation. ${ }^{9}$

20) Concurrent signs, symptoms, and diseases other than the event described.

21) Values and units of routinely measured parameters $\left(\mathrm{cm},{ }^{\circ} \mathrm{C}\right.$, etc.)-in particular those indicating the severity of VTD. Normal ranges used in the particular laboratory or clinic setting should be reported for each parameter measured. The date of specimen collection and/or measurement for each parameter should also be recorded.

22) Results of laboratory examinations, other clinical tests, surgical and/or pathological findings and diagnoses. If possible, attempts should be made to have laboratory testing performed at reliable and accredited laboratories. If more than one measurement of a particular parameter is taken and recorded, the value corresponding to the largest deviation from the expected normal value or range of that parameter should be reported (e.g., highest serum creatinine, lowest platelet count).

23) Treatment given for VTD (especially hospitalization, supplemental oxygen, intravenous fluids, vasopressor drugs, mechanical ventilation, hemodialysis, steroids, antiviral drugs) and names and addresses of treating physicians and/or institutions.

24) Detailed description of the outcome at last observation ${ }^{9}$ of VTD should be clearly described, such as

- Recovery to pre-immunization health status.

- Spontaneous resolution.

- Ongoing treatment.

- Persistence of the event.

- Sequelae from VTD itself.

- Significant complications of treatment.

- Death; and

- description of any other outcome.

25) Medical confirmation of the event (i.e., patient seen by physician).

26) Presence or absence of concurrent local disease outbreaks or recent travel to an area affected by a disease outbreak (e.g., yellow fever).

\subsubsection{Miscellaneous/general recommendations}

27) The duration of surveillance for VTD should be predefined where applicable (e.g., clinical studies or active follow-up) based on

- Biologic characteristics of the vaccine (e.g., live attenuated versus inactivated component vaccines).

- Biologic characteristics of the vaccine-targeted disease.

- Biologic characteristics of VTD including patterns identified from previous reports (e.g., associated with yellow fever vaccine); and

\footnotetext{
5 The date and/or time of onset is defined as the date postimmunization when the first sign or symptom suggestive of VTD occurred. This may only be possible to determine in retrospect.

6 The date and/or time of first observation of the first sign or symptom suggestive of VTD can be used, if date/time of onset is not known.

7 The date of diagnosis of an episode is the date postimmunization the event met the case definition at any level.

8 The end of an episode is defined as the date the event no longer meets the case definition.

9 VTD not resolved at the end of a predefined follow-up period may be followed up as clinically necessary, and additional reporting should be encouraged to describe progress until the clinical status is stable. The date of last observation is the date of the last clinical evaluation of the patient with VTD. "Persistence of event" refers to events continuing to meet the case definition beyond the follow-up period. "Sequelae" are long-term clinical consequences resulting from VTD.
}

- biologic characteristics of the target population (e.g., nutrition, underlying disease such as immunodepressing illness).

28) The WG recommends that reports of VTD should be collected at a minimum for all cases with symptom onset within 30 days following vaccination, based on previous reports of VTD.

29) Methods of data collection should be consistent within and between study groups or surveillance systems, if applicable.

30) The frequency and duration of follow-up for VTD, reported during the surveillance period, should be daily for the first week, weekly for the rest of the first month, and then monthly for a total of 6 months or until a new status quo is reached, whichever comes sooner. Follow-up of reported events should attempt to verify and complete the collection of information as outlined in Section 3.1.

\subsection{Data analysis}

The following guidelines represent a desirable standard for analysis of data on VTD to allow for comparability of data and are recommended as a supplement to data analyzed for the setting and any specific study question(s).

31) Reported events could be classified in one of the following five categories noted below. Events that meet the case definition should be classified according to the levels of diagnostic certainty as specified in the case definition. Events that do not meet the case definition should be classified in one of the additional two categories for analysis.

\section{Event classification in 5 categories ${ }^{10}$ \\ Event meets case definition \\ Main categories}

1) Level 1: criteria as specified in the case definition for VTD.

2) Level 2: criteria as specified in the case definition for VTD.

3) Level 3: criteria as specified in the case definition for VTD.

\section{Event does not meet case definition ${ }^{11}$ Additional categories for analysis}

4) Reported VTD with insufficient evidence to meet the case definition. ${ }^{12}$

5) Not a case of VTD. ${ }^{13}$

\footnotetext{
10 To determine the appropriate category, the user should first establish whether a reported event meets the criteria for the lowest applicable level of diagnostic certainty, i.e., Level 3. If the lowest applicable level of diagnostic certainty of a definition is met and there is evidence that the criteria of the next higher level of diagnostic certainty are met, the event should be classified in the next higher category. This approach should be continued until the highest level of diagnostic certainty for given event has been determined. If the lowest level of a case definition is not met the user should confirm that none of the higher levels of diagnostic certainty are met before finally classifying the event in category 4 or 5 .

11 If an adverse event (AE) reported as VTD does not meet Levels 1, 2, or 3 of the VTD case definition, then additional diagnostic studies should be done to further search for diagnoses not previously considered that could explain the clinical picture of the $\mathrm{AE}$

12 If the evidence available for an event is insufficient to permit classification by any level of diagnostic certainty (e.g., because of missing information), such an event should be categorized as "Reported VTD with insufficient evidence to meet the case definition." Notations should be made as to what evidence is missing.

13 If there is adequate evidence that an event does not meet the case definition, the event should be rejected and should be reported as "Not a case of VTD." Such evidence is considered adequate if the investigation reveals negative findings for all necessary criteria (necessary conditions) for diagnosis. Such an event should be rejected and classified as "Not a case of VTD."
} 
32) Events following YF vaccine administration that meet the case definition (Level 1, Level 2, or Level 3 of diagnostic certainty) or are classified as reports of VTD with insufficient evidence to meet the case definition should be further classified into one of the following categories, using the YF vaccine causality algorithm in Appendix $\mathrm{A}^{14}$ :

1) Definite yellow fever vaccine-associated causality.

2) Probable yellow fever vaccine-associated causality.

3) Suspect yellow fever vaccine-associated causality.

4) Insufficient data to determine yellow fever vaccine-associated causality.

33) The interval between immunization and VTD should be specified by using the date/time of immunization and the date/time of onset ${ }^{5}$ or first observation ${ }^{6}$ or diagnosis ${ }^{7}$, whichever is most appropriate. The day of immunization is commonly considered day zero. Whichever numerical designation is used for the day of immunization should be clearly stated by the reporter (e.g., day 0 or day 1 ).

34) The duration of possible VTD should be analyzed as the interval between date/time of onset ${ }^{5}$ or first observation ${ }^{6}$ or diagnosis $^{7}$ and the end of episode ${ }^{8}$ or last observation ${ }^{9}$. Whatever start and ending dates are used, they should be clearly defined and used consistently within and across study groups and surveillance systems. For any cases that are an exception to the standard used (e.g., because of missing data), reports should note the reason(s) for the difference(s).

35) If more than one measurement of a particular parameter is taken and recorded, the value corresponding to the largest deviation from the expected normal value or range of that parameter should be used as the basis for analysis (e.g., highest creatinine, lowest platelet count). Analysis may also include other characteristics like qualitative patterns of criteria defining the event (e.g., periodicity, frequency, etc.).

36) Given that VTD is a rare adverse event following immunization, the reported values or time course should be presented individually as case reports.

37) Data on VTD cases should be compared with those obtained from one or more appropriately selected and documented comparison group(s) and should be analyzed by study arm and dose, as applicable.

38) Events should be coded as either unknown or missing under the following circumstances: for missing events, no data were available through record review; for unknown events, data were available but the reporter was uncertain of the answer.

\subsection{Data presentation}

The following guidelines represent a desirable standard for presentation or publication of analyzed AEFI data to allow comparability in vaccine safety. They are not guidelines for primary reporting of AEFI to a study monitor. Additional information collected and analyzed may be presented depending on the study question and setting. The WG recommends that researchers also refer to other guidelines, including CONSORT (Consolidated standards of reporting trials), QUORUM (Improving the quality of reports of meta-analyses of randomized controlled trials), TREND (Transparent reporting of evaluations with nonrandomized designs), STROBE (Strengthening the reporting of observational

\footnotetext{
14 The YF vaccine causality classification scheme detailed in this document is different from the more general WHO scheme for causality assessment of AEFI, currently undergoing revision and available at: http://www.who.int/vaccinesdocuments/DocsPDF05/815.pdf.
}

studies in epidemiology),and MOOSE (Meta-analysis of observational studies in epidemiology) for presentation and publication of randomized controlled trials, meta-analyses, nonrandomized designs, observational studies, and systematic reviews of vaccine safety studies, respectively [47-51].

39) Data on VTD should be presented in accordance with the data analysis guidelines in Section 3.2.

40) Terms to describe VTD, such as "low-grade," "mild," "moderate," "high," "severe," or "significant," are highly subjective, prone to wide interpretation, and should be avoided unless validated or clearly defined.

41) Data should be presented with numerator and denominator $(\mathrm{n} / \mathrm{N})$ and not only in percentages or graphical illustrations. The denominator should be clearly defined (e.g., number of doses delivered for the campaign or lot number). These data should be further analyzed by lot or vaccine, if applicable.

42) If the distribution of data is skewed, median and range are usually the more appropriate statistical descriptors than a mean. However, the mean and standard deviation, as well as the median and range, should also be provided to permit metaanalysis.

43) The incidence ${ }^{15}$ of events meeting the case definition should be presented and clearly identified as such in the text. The population for which the incidence is calculated and the source of these data should be clearly described (e.g., per doses distributed or administered).

44) Any publication of VTD data should include as detailed as possible a description of the methods used for data collection and analysis. It is essential to specify (as applicable):

- The study design.

- The study group(s) including comparison group(s).

- The instrument of data collection (e.g., standardized questionnaire, diary card).

- The method, frequency, and duration of monitoring for VTD.

- Whether the day of immunization was considered "day zero" or "day one" in the analysis.

- Whether the date of onset ${ }^{5}$ and/or the date of first observation ${ }^{6}$ and/or the date of diagnosis ${ }^{7}$ and the end of episode ${ }^{8}$ and/or last observation ${ }^{9}$ were used for analysis.

- The data analysis plan per protocol, and the statistical plan; and any amendments to these sections of the protocol added during the study.

- The trial profile indicating participant flow during a study, including drop-outs and withdrawals, to indicate the size and nature of the respective groups under investigation; and

- Reference of the case definition used (Brighton or other) for VTD in the abstract or methods section of a publication. ${ }^{16}$

\section{Acknowledgments}

The authors are grateful for the support and helpful comments from members of the Brighton Collaboration Science Board (Mike Blum, Jim Buttery, Steve Black, Paul T. Heath, Egeruan Babatunde Imoukhuede, Hector Izurieta, Najwa Khuri-Bulos, Heidi Larson, Miriam Sturkenboom), additional Working Group members (Oyewale Tomori, Lewis Markoff), and participants in the Reference

\footnotetext{
15 For example, 10 cases of VTD among 100,000 doses administered, or 2 cases of VTD on day 1, 3 cases on day 2, 10 cases on day 3 following immunization, or 10 cases after the first dose, 1 case after the second dose, 0 cases after the third dose.

16 Use of this or AEFI-specific documents developed by the Brighton Collaboration should be referenced by referring to the link on the Brighton Collaboration website (https://brightoncollaboration.org/public).
} 
Group (Novilia S. Bachtiar, Salem Banajeh, Lulu Bravo, Arani Chatterjee, Ivan Edelberto Cuevas-Valdespino, Jean-Louis Excler, Cristian Falup-Pecurariu, Rohini Fernandopulle, Karl Gallegos, Roxana Ghanaie, Shah Hossain, Wan-Ting Huang, Isme Humolli, Bettina Klug, Sonali Kochhar, Cece Vieux Kolie, Merita Kucuku, Sanja Kurecic Filipovic, Chandrakant Lahariya, David Nalin, Jose Navarro-Alonso, Suchitra Nimmannitya, Karaman Pagava, Farshad Pourmalek, Ranjan Ramasamy, Isabelle Rouleau, Eliane Matos dos Santos, Carmela Santuccio, Claudia Schmidt, Stephen J. Seligman, Joseph Sliman, Iris Thorogood, Georgios Trimis, Kristy Van Dinther, Frederick Varricchio, Omala Wimalaratne, Virginia Wong, Tene Marceline Yameogo, Thaddeus Zajdowicz, Patrick Zuber).The authors are also grateful to the Brighton Collaboration Management Team (Jan Bonhoeffer, Simone Casagrande, Sabine Faisst, Yulin Li, Norbert Sommerfeld, Daniel Weibel), CDC staff (April Compingbutra and Theresa Sommers), Anne Eisinga for the systematic literature search, and scientific experts consulted as part of the process (Thomas P. Monath, Sherif Zaki).

\section{Appendix A.}

\section{A.1. Further classification of a VTD case as an adverse event} following immunization with yellow fever vaccine

\section{A.1.1. Causal association}

Vaccine strain 17D YF virus can be detected in blood by virus culture or viral RNA amplification using reverse transcriptasepolymerase chain reaction (RT-PCR). Viremia with 17D YF virus occurs normally after primary YF vaccination, but not with booster doses [52,53]. It has been demonstrated by plaque-forming assay that the normal viremia after primary vaccination with17D YF virus occurs at 4-6 days postvaccination in most persons and disappears by day 10 [53-55]. The peak viremia is less than $100 \mathrm{PFU} / \mathrm{mL}$ [52-54]. Although the detection of circulating 17D YF viral RNA by RT-PCR is more sensitive than virus isolation [52], only limited data have been published characterizing the peak and time course for circulating 17D YF viral RNA in normal vaccine recipients. Several studies have detected 17D YF viral RNA by RT-PCR in the blood of healthy subjects at days 6-11 after vaccination, although only in a small percentage of subjects at day 11 [52,56,57][CDC, unpublished data, 2010]. Depending on the study, 17D YF viral RNA was undetectable by day 11 or 14 . These data on the kinetics of 17D YF virus in the blood of healthy vaccines are instrumental in establishing the various levels of certainty for YF vaccine causality in the algorithm below.

Tissue can be tested for the presence of 17D YF virus by using the techniques of virus isolation, RT-PCR, and immunohistochemistry (IHC). With rare exceptions, human tissue has been available only postmortem for testing in fatal cases of YEL-AVD, since biopsy is contraindicated in severe YEL-AVD with coagulopathy because of the risk of significant hemorrhage. A biodistribution study of healthy vaccinated monkeys detected the 17D YF virus in the liver of one monkey and in the lymphoid tissue of several [58]. Consequently, there is reason to believe that 17D YF virus might also be distributed in the tissues of healthy human vaccines. However, no data exist regarding the normal kinetics and distribution of $17 \mathrm{D}$ YF virus in human tissue following vaccination, which limits the degree of certainty that can be assigned to positive YF test results of tissue in the causality algorithm.

Characteristic histopathologic findings in the liver described in fatal cases of wild type YF and YEL-AVD are Councilman bodies and midzonal necrosis. However, these findings are not unique to these diseases [20]. A limitation of IHC is that it is usually performed with a polyclonal antibody that reacts to both wild type YF and 17D YF virus. Because of their lack of specificity for 17D YF virus, both IHC and histopathology test results need to be interpreted in light of the patient's potential to have been exposed to wild type YF virus around the time of vaccination (i.e., travel to or residence in an area with known YF virus circulation).

\section{A.1.2. Case classification}

This algorithm is based on the kinetics of 17D YF vaccine viremia in healthy vaccinees and assumes a normal immune system. Individuals with immunosuppression or immune dysregulation (inherited, acquired or medically induced) who are vaccinated with 17D YF virus might have altered response with either higher or longer duration of viremia. Since there are no data on the kinetics of viremia following YF vaccination in persons with altered immune systems, these guidelines and criteria might not be as applicable for determining vaccine causality of AEFI among such patients and should be used with caution.

Testing for 17D YF vaccine virus should be performed by a laboratory that is proficient in and has previously conducted YF testing, including the differentiation of vaccine from wild-type virus strains; generally this will be a national or regional reference laboratory.

\section{VTD - causality criteria for yellow fever vaccine ${ }^{14}$}

To be classified as one of the four categories of yellow fever vaccineassociated causality below, a reported case of VTD should meet all the following criteria:

- The case is an adverse event following documented or confirmed YF vaccination that either meets the VTD case definition (Level 1,2 , or 3 ) or is classified as reported VTD with insufficient evidence to meet the case definition

- Symptom onset is within 10 days of vaccination

- There is no laboratory evidence of another diagnosis

\section{Definite yellow fever vaccine-associated causality}

One or more of the following are present:

- Yellow fever $17 \mathrm{D}^{\mathrm{a}}$ virus isolation from blood $>10$ days postvaccination

- Yellow fever $17 \mathrm{D}^{\mathrm{a}}$ virus concentration in blood $\geq 3 \log 10 \mathrm{pfu} / \mathrm{mL}$ on any day

- Yellow fever $17 D^{a}$ viral RNA amplification from blood $\geq 14$ days post vaccination

- Isolation of yellow fever $17 \mathrm{D}^{\mathrm{a}}$ virus OR amplification of yellow fever $17 \mathrm{D}^{\mathrm{a}}$ viral RNA from tissue AND histopathology consistent with yellow fever (e.g., liver midzonal necrosis, Councilman bodies)

- YF virus-specific antigen in tissue with characteristic vaccine-associated distribution (extrahepatic or mesenchymal cell involvement) demonstrated by immunohistochemistry (IHC) ${ }^{\mathrm{b}}$ AND histopathology consistent with yellow fever (e.g., liver midzonal necrosis, Councilman bodies) AND no history of being in a yellow fever-endemic or -epidemic area within 10 days of symptom onset

2. Probable yellow fever vaccine-associated causality

One or more of the following are present:

- Yellow fever $17 \mathrm{D}^{\mathrm{a}}$ virus isolation from blood 8-10 days post vaccination

- Yellow fever $17 \mathrm{D}^{\mathrm{a}}$ virus concentration in blood $\geq 2 \log 10 \mathrm{pfu} / \mathrm{mL}$ but $<3 \log 10 \mathrm{pfu} / \mathrm{mL}$ on any day $1-10$ days postvaccination

- Yellow fever $17 D^{a}$ viral RNA amplification from blood $\geq 11$ and $<14$ days postvaccination

- Isolation of yellow fever $17 \mathrm{D}^{\mathrm{a}}$ virus OR amplification of yellow fever $17 \mathrm{D}^{\mathrm{a}}$ viral RNA from tissue ${ }^{c}$

- Histopathology consistent with yellow fever (e.g., liver midzonal necrosis, Councilman bodies) AND no history of being in a yellow fever-endemic or -epidemic area within 10 days of symptom onset ${ }^{c}$

3. Suspect yellow fever vaccine-associated causality

One or more of the following are present:

- Histopathology consistent with yellow fever (e.g., liver midzonal necrosis, Councilman bodies) AND history of being in a yellow fever-endemic or -epidemic area within 10 days of symptom onset

- YF virus-specific antigen in tissue demonstrated by immunohistochemistry (IHC) $)^{b}$ AND history of being in a yellow fever-endemic or -epidemic area within 10 days of symptom onset

4. Insufficient data to determine yellow fever vaccine-associated causality One of the following:

- No yellow fever testing done 
OR

- Yellow fever testing done and test results do not meet any of the criteria for causality Levels 1,2 , or 3 above ${ }^{\mathrm{d}}$

${ }^{\mathrm{a}}$ Confirmed as 17D virus by nucleotide sequencing.

bImmunohistochemistry (IHC) performed by using polyclonal antibody to yellow fever viral antigen that reacts to both 17D yellow fever virus and wild type yellow fever virus.

${ }^{c}$ If both the fourth and fifth criteria for probable YF vaccine-associated causality are present, this is equivalent to the fourth criteria for definite YF vaccine-associated causality. In this case, the condition of "no history of recently being a in a YFendemic/epidemic area within 10 days of symptom onset" is unnecessary, because the possibility of wild type YF virus infection has been eliminated by the identification of 17D YF vaccine virus in tissue.

${ }^{\mathrm{d}}$ The presence or absence of serum YF virus-specific antibodies ( $\operatorname{IgM}$ or $\operatorname{IgG}$ ) has not been demonstrated to correlate with or be predictive of YF vaccine causality in cases of VTD.

\section{A.2. Other routes of transmission of yellow fever vaccine virus}

Although direct vaccination is by far the predominant route of exposure to 17D YF vaccine virus, breastfeeding and transfusion are other potential, albeit rare, routes of exposure. One confirmed and two probable cases have been reported of breastfeeding-associated transmission of 17D YF virus resulting in YF vaccine-associated neurologic disease (encephalitis) in very young, exclusively breastfed infants [59-61]. However, the precise mechanism of transmission (e.g., transmission through breast milk or direct blood-to-blood transmission involving excoriated maternal nipple and infant oral mucosa) has not been established. In addition, transfusion transmission of 17D YF virus to recipients of various blood products donated by recently vaccinated persons has been confirmed serologically [62]. No adverse events attributable to the 17D YF virus were identified in the recipients of the blood products. To date, however, no data suggest that YEL-AVD has been associated with any route of 17D YF virus exposure other than by direct vaccination.

\section{Appendix B.}

\section{B.1. Data collection checklist for viscerotropic disease (VTD)}

This checklist serves as a template for data abstraction based on criteria listed in the case definition and guidelines for data collection. It is intended to assist with data collection in study protocols and active follow-up in surveillance systems. Additional information or a different format may be required, depending on the study question and setting.

The Brighton VTD Working Group recommended that reports be collected from all persons with symptoms consistent with VTD within 30 days of their vaccination.

\section{A. Source of information/reporter}

In accordance with country-specific data protection laws.

\begin{tabular}{|c|c|c|c|c|c|}
\hline a. Date of report & \multicolumn{5}{|c|}{$\left.\frac{1}{(\mathrm{~mm} / \mathrm{dd}} / \overline{\text { yyyy }}\right)$} \\
\hline $\begin{array}{l}\text { b. Reporter's } \\
\text { name }\end{array}$ & \multicolumn{5}{|l|}{ Name: } \\
\hline $\begin{array}{l}\text { c. Reporter's } \\
\text { contact } \\
\text { information }\end{array}$ & \multicolumn{4}{|c|}{$\begin{array}{l}\text { Address: } \\
\text { Telephone number: } \\
\text { E-mail address: }\end{array}$} & \\
\hline $\begin{array}{l}\text { d. Reporter's } \\
\text { relationship to the } \\
\text { vaccine recipient }\end{array}$ & $\begin{array}{l}\text { [ ] Immunizer } \\
\text { Specify } \\
\text { (clinician, nurse, } \\
\text { etc.) }\end{array}$ & $\begin{array}{l}\text { [] Attending } \\
\text { physician }\end{array}$ & $\begin{array}{l}\text { [ ] Family member } \\
\text { Specify }\end{array}$ & $\begin{array}{l}{[] \text { Self }} \\
\text { (vaccine } \\
\text { recipient) }\end{array}$ & $\begin{array}{l}\text { [ ] Other } \\
\text { Specify }\end{array}$ \\
\hline
\end{tabular}

B. Vaccinee/Control details

In accordance with country-specific data protection laws.

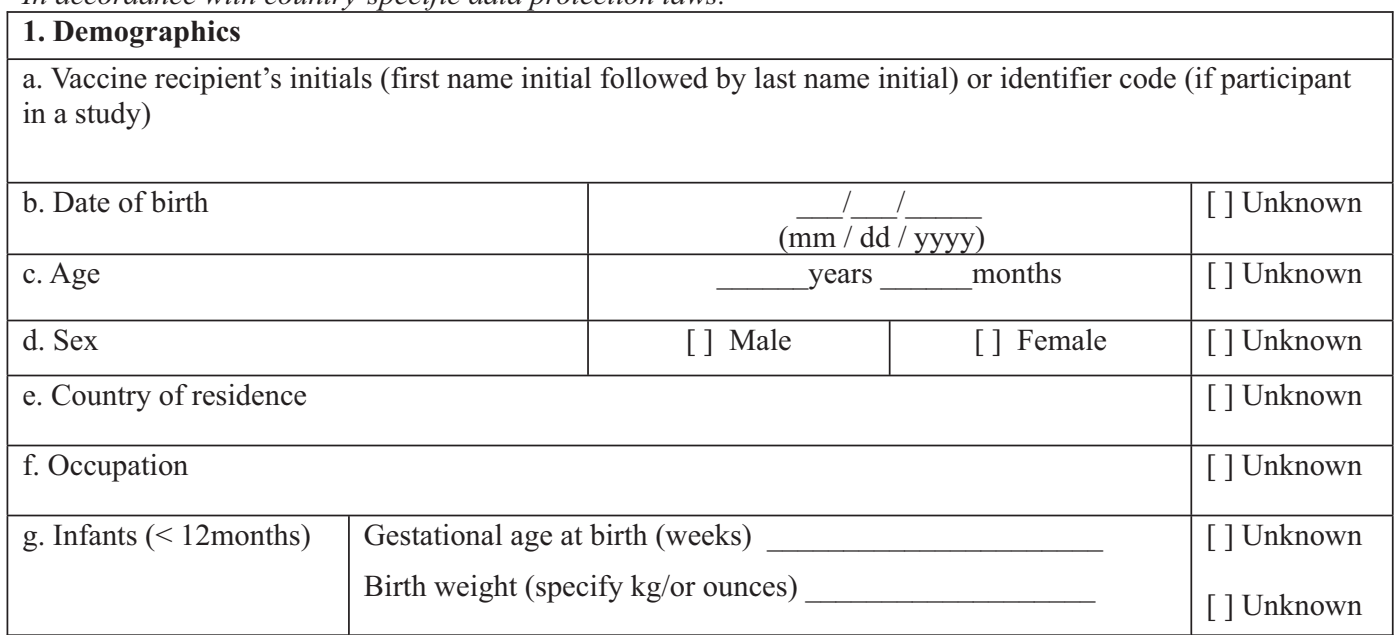




\section{Past clinical / past immunization history}

a. Any past medical condition, including underlying disease, hospitalizations, surgeries (e.g., thymectomy), and pre-immunization signs and symptoms

If YES, please describe in detail

\begin{tabular}{|l|l|l} 
[ ] Yes & [ ] No & [ ] Unknown
\end{tabular}

b. Any medication prior to, during, and after vaccination. Do not include any medications used to treat VTD. Include both prescription and nonprescription medications, as well as medications with long half-life or long-term effect (* ${ }^{*}$ see guideline 10 in section 3.1.2.2 of the VTD case definition document).

\begin{tabular}{|c|c|c|c|c|}
\hline $\begin{array}{l}\text { Medication } \\
\text { (provide generic } \\
\text { name, if possible) }\end{array}$ & Start date & $\begin{array}{c}\text { Stop date } \\
\text { or still taking }\end{array}$ & Dose & $\begin{array}{c}\text { Route of } \\
\text { administration }\end{array}$ \\
\hline & $(\overline{\mathrm{mm}} / \mathrm{dd} / \mathrm{l} / \mathrm{yyy})$ & $\begin{array}{c}(\overline{\mathrm{mm}} / \overline{\mathrm{dd} / \text { yyyy })} \\
\square \text { Still taking }\end{array}$ & & \\
\hline & $(\overline{\mathrm{mm}} / \mathrm{dd} / \mathrm{yyyy})$ & $\begin{array}{c}(\overline{\mathrm{mm}} / \overline{\mathrm{dd}} / \mathrm{l} \text { yyy }) \\
\square \text { Still taking }\end{array}$ & & \\
\hline & $(\overline{\mathrm{mm}} / \mathrm{dd} / \mathrm{yyyy})$ & $\begin{array}{c}(\overline{\mathrm{mm}} / \overline{\mathrm{dd} / \text { yyyy })} \\
\square \text { Still taking }\end{array}$ & & \\
\hline & $(\overline{\mathrm{mm}} / \mathrm{dd} / \mathrm{l} / \mathrm{yyy})$ & $\begin{array}{c}(\overline{\mathrm{mm}} / \overline{\mathrm{dd} / \text { yyyy })} \\
\square \text { Still taking }\end{array}$ & & \\
\hline & $\left(\overline{\mathrm{mm}} / \frac{1}{\mathrm{dd} / \text { yyyy })}\right.$ & $\begin{array}{l}\left(\frac{\mathrm{mm} / \mathrm{dd} / \mathrm{yyyy})}{}\right) \\
\square \text { Still taking }\end{array}$ & & \\
\hline
\end{tabular}

c. Past immunization history: List prior immunizations received more than 30 days before VTD symptom onset. Include any vaccines known to cause VTD, such as YF vaccine, and any adverse event following immunization ever experienced (can attach immunization record). 


\section{Details of the recent immunizations}

For all immunizations given within 30 days prior to onset of VTD symptoms (if more than 5 vaccines were given, please copy table and provide the information for each of the vaccines)

\begin{tabular}{|c|c|c|c|c|c|}
\hline \multicolumn{6}{|c|}{ 1. Vaccine and diluent information } \\
\hline & Vaccine 1 & Vaccine 2 & Vaccine 3 & Vaccine 4 & Vaccine 5 \\
\hline \multicolumn{6}{|l|}{$\begin{array}{l}\text { a. Vaccine trade } \\
\text { name }\end{array}$} \\
\hline \multicolumn{6}{|l|}{$\begin{array}{l}\text { b. Vaccine } \\
\text { manufacturer }\end{array}$} \\
\hline \multicolumn{6}{|l|}{$\begin{array}{l}\text { c. Vaccine lot } \\
\text { number }\end{array}$} \\
\hline $\begin{array}{l}\text { d. Vaccine } \\
\text { expiration date }\end{array}$ & $\frac{1}{(\mathrm{~mm} / \mathrm{dd} / \mathrm{yyyy})}$ & $(\overline{\mathrm{mm}} / \mathrm{dd} / \mathrm{l} / y \mathbf{yy})$ & $(\overline{\mathrm{mm}} / \mathrm{dd} / \mathrm{l} / \overline{y y y})$ & $\frac{1}{(\mathrm{~mm} / \mathrm{dd} / \text { yуyу })}$ & $\frac{1}{(\mathrm{~mm} / \mathrm{dd} / \mathrm{yyyy})}$ \\
\hline $\begin{array}{l}\text { e. Multi- or mono- } \\
\text { dose vial }\end{array}$ & $\begin{array}{l}\text { [] multi- } \\
\text { [] mono- }\end{array}$ & $\begin{array}{l}\text { [] multi- } \\
\text { [] mono- }\end{array}$ & $\begin{array}{l}\text { [] multi- } \\
\text { [] mono- }\end{array}$ & $\begin{array}{l}\text { [] multi- } \\
\text { [] mono- }\end{array}$ & $\begin{array}{l}\text { [] multi- } \\
\text { [] mono- }\end{array}$ \\
\hline \multicolumn{6}{|l|}{$\begin{array}{l}\text { f. Volume }(\mathrm{mL}) \text { of } \\
\text { dose }\end{array}$} \\
\hline $\begin{array}{l}\text { g. Diluent lot } \\
\text { number }\end{array}$ & $\begin{array}{l}\overline{\text { Not applicable }} \\
\text { (premixed) }\end{array}$ & $\begin{array}{c}\overline{\text { Not applicable }} \\
\text { (premixed) }\end{array}$ & $\begin{array}{c}\square \text { Not applicable } \\
\text { (premixed) }\end{array}$ & $\begin{array}{c}\square \text { Not applicable } \\
\text { (premixed) }\end{array}$ & $\begin{array}{c}\square \text { Not applicable } \\
\text { (premixed) }\end{array}$ \\
\hline $\begin{array}{l}\text { h. Diluent } \\
\text { expiration date }\end{array}$ & $\begin{array}{l}\frac{1}{(\mathrm{~mm} / \mathrm{dd} / \mathrm{yyyy})} \\
\square \text { Not applicable } \\
\quad \text { (premixed) }\end{array}$ & $\begin{array}{c}(\overline{\mathrm{mm}} / \overline{\mathrm{dd} / \mathrm{yyyy})} \\
\square \begin{array}{c}\text { Not applicable } \\
\text { (premixed) }\end{array}\end{array}$ & $\begin{array}{c}(\overline{\mathrm{mm}} / \overline{\mathrm{dd}} / \mathrm{yyyy}) \\
\square \text { Not applicable } \\
\text { (premixed) }\end{array}$ & $\begin{array}{c}\frac{/}{(\mathrm{mm} / \mathrm{dd} / \mathrm{yyyy})} \\
\square \text { Not applicable } \\
\text { (premixed) }\end{array}$ & $\begin{array}{c}\frac{1}{(\mathrm{~mm} / \mathrm{dd} / \mathrm{yyyy})} \\
\square \text { Not applicable } \\
\text { (premixed) }\end{array}$ \\
\hline $\begin{array}{l}\text { i. Dose number (if } \\
\text { part of series) }\end{array}$ & _ of __ & _ of & _ of __ & _ of __ & _ of \\
\hline \multicolumn{6}{|c|}{ 2. Information on vaccine administration } \\
\hline $\begin{array}{l}\text { j. Date of } \\
\text { immunization }\end{array}$ & $\frac{/}{(\mathrm{mm} / \mathrm{dd} / \mathrm{yyyy})}$ & $(\overline{\mathrm{mm}} / \mathrm{dd} / \mathrm{l} / \mathrm{lyy})$ & $(\overline{\mathrm{mm}} / \mathrm{dd} / \mathrm{l} y \mathrm{yy})$ & $\frac{/}{(\mathrm{mm} / \mathrm{dd} / \mathrm{yyyy})}$ & $\left(\overline{\mathrm{mm}} / \frac{1}{\mathrm{dd} / \mathrm{y} y y y)}\right.$ \\
\hline $\begin{array}{l}\text { k. Time of } \\
\text { immunization }\end{array}$ & {$[$ [ ] am [ ]pm } & {$[$ [ ] am [ ]pm } & {$[$ [ ] am [ ]pm } & {$[$ [ ] } & {$[$ [ ] am [ ]pm } \\
\hline
\end{tabular}




\begin{tabular}{|c|c|c|c|c|c|c|c|}
\hline & Vaccine 1 & Vaccine 2 & Vaccine 3 & \multicolumn{2}{|c|}{ Vaccine 4} & \multicolumn{2}{|c|}{ Vaccine 5} \\
\hline \multicolumn{8}{|l|}{$\begin{array}{l}\text { 1. Geographic } \\
\text { location of } \\
\text { immunization } \\
\text { (city/town, } \\
\text { state/province, } \\
\text { country) }\end{array}$} \\
\hline $\begin{array}{l}\text { m. Name, address, } \\
\text { telephone number } \\
\text { of clinic where } \\
\text { vaccine(s) given }\end{array}$ & & $\begin{array}{l}\overline{\text { [ ] Same clinic as }} \\
\text { vaccine } 1\end{array}$ & $\begin{array}{l}\text { [] Same clinic as } \\
\text { vaccine } 1\end{array}$ & \multicolumn{2}{|c|}{$\begin{array}{l} \\
\text { ] Same clinic } \\
\text { as vaccine } 1\end{array}$} & \multicolumn{2}{|c|}{$\begin{array}{l} \\
\text { [ ] Same clinic as } \\
\text { vaccine } 1\end{array}$} \\
\hline $\begin{array}{l}\text { n. Anatomic site of } \\
\text { immunization (the } \\
\text { location on the } \\
\text { patient's body } \\
\text { where the vaccine } \\
\text { was administered) }\end{array}$ & $\begin{array}{l}\text { [ ] Left [] Right } \\
\text { [ ] Unknown }\end{array}$ & $\begin{array}{l}\text { [ ] Left [ ] Right } \\
\text { [ ] Unknown }\end{array}$ & $\begin{array}{l}\text { [] Left [] Right } \\
\text { [] Unknown }\end{array}$ & \multicolumn{2}{|c|}{$\begin{array}{l}\text { [ ] Left [ ]Right } \\
\text { [ ] Unknown }\end{array}$} & \multicolumn{2}{|c|}{$\begin{array}{l}\text { [ ] Left [ ] Right } \\
\text { [ ] Unknown }\end{array}$} \\
\hline $\begin{array}{l}\text { o. Route of } \\
\text { administration }\end{array}$ & \begin{tabular}{l} 
[ ] Intradermal \\
[ ] Subcutaneous \\
[ ] Intramuscular \\
[ ] Oral \\
[ ] Intranasal \\
[ ] Needle-free \\
\\
\multicolumn{1}{c}{ (type, size) } \\
[ ] Other injection \\
device
\end{tabular} & \begin{tabular}{l} 
[ ] Intradermal \\
[ ] Subcutaneous \\
[ ] Intramuscular \\
[ ] Oral \\
[ ] Intranasal \\
[ ] Needle-free \\
\\
\multicolumn{2}{c}{ (type, size) } \\
[ ] Other injection \\
device
\end{tabular} & $\begin{array}{l}\text { [] Intradermal } \\
\text { [ ] Subcutaneous } \\
\text { [ ] Intramuscular } \\
\text { [ ] Oral } \\
\text { [ ] Intranasal } \\
\text { [ ] Needle-free }\end{array}$ & \multicolumn{2}{|c|}{$\begin{array}{l}\text { [ ] Intradermal } \\
\text { [ ] Subcutaneous } \\
\text { [ ] Intramuscular } \\
\text { [ ] Oral } \\
\text { [ ] Intranasal } \\
\text { [ ] Needle-free }\end{array}$} & \multicolumn{2}{|c|}{$\begin{array}{l}\text { [ ] Intradermal } \\
\text { [ ] Subcutaneous } \\
\text { [ ] Intramuscular } \\
\text { [ ] Oral } \\
\text { [ ] Intranasal } \\
\text { [ ] Needle-free }\end{array}$} \\
\hline \multirow{2}{*}{\multicolumn{3}{|c|}{ p. Context of immunization }} & \multicolumn{5}{|c|}{$\begin{array}{l}\text { Vheck the box which best indicates the reason for } \\
\text { administration of each vaccine (numbered as } \\
\text { above) }\end{array}$} \\
\hline & & & 1 & 2 & 3 & 4 & 5 \\
\hline \multicolumn{3}{|c|}{ Routine childhood immunization program } & {[]} & {[]} & [ ] & {[]} & [ ] \\
\hline \multicolumn{3}{|c|}{ Preventive mass immunization campaign } & [] & {[]} & [ ] & {[]} & [] \\
\hline \multicolumn{3}{|c|}{ Outbreak response immunization campaign } & {[]} & {[]} & {[]} & [ ] & {[]} \\
\hline \multicolumn{3}{|c|}{ Routine adult immunization } & {[]} & {[]} & [ ] & [ ] & {[]} \\
\hline \multicolumn{3}{|c|}{ International travel } & [ ] & [ ] & [ ] & [ ] & {[]} \\
\hline \multicolumn{3}{|c|}{ Domestic travel (nonendemic to endemic area) } & [ ] & [ ] & [ ] & [ ] & {[]} \\
\hline \multicolumn{3}{|c|}{ Occupational risk } & {[]} & [ ] & {[]} & [ ] & {[]} \\
\hline \multicolumn{3}{|c|}{ Military requirement } & [ ] & {[]} & [ ] & [ ] & {[]} \\
\hline \multicolumn{3}{|c|}{ Other (specify) } & [] & {[]} & {[]} & [ ] & {[]} \\
\hline
\end{tabular}


D. The adverse event

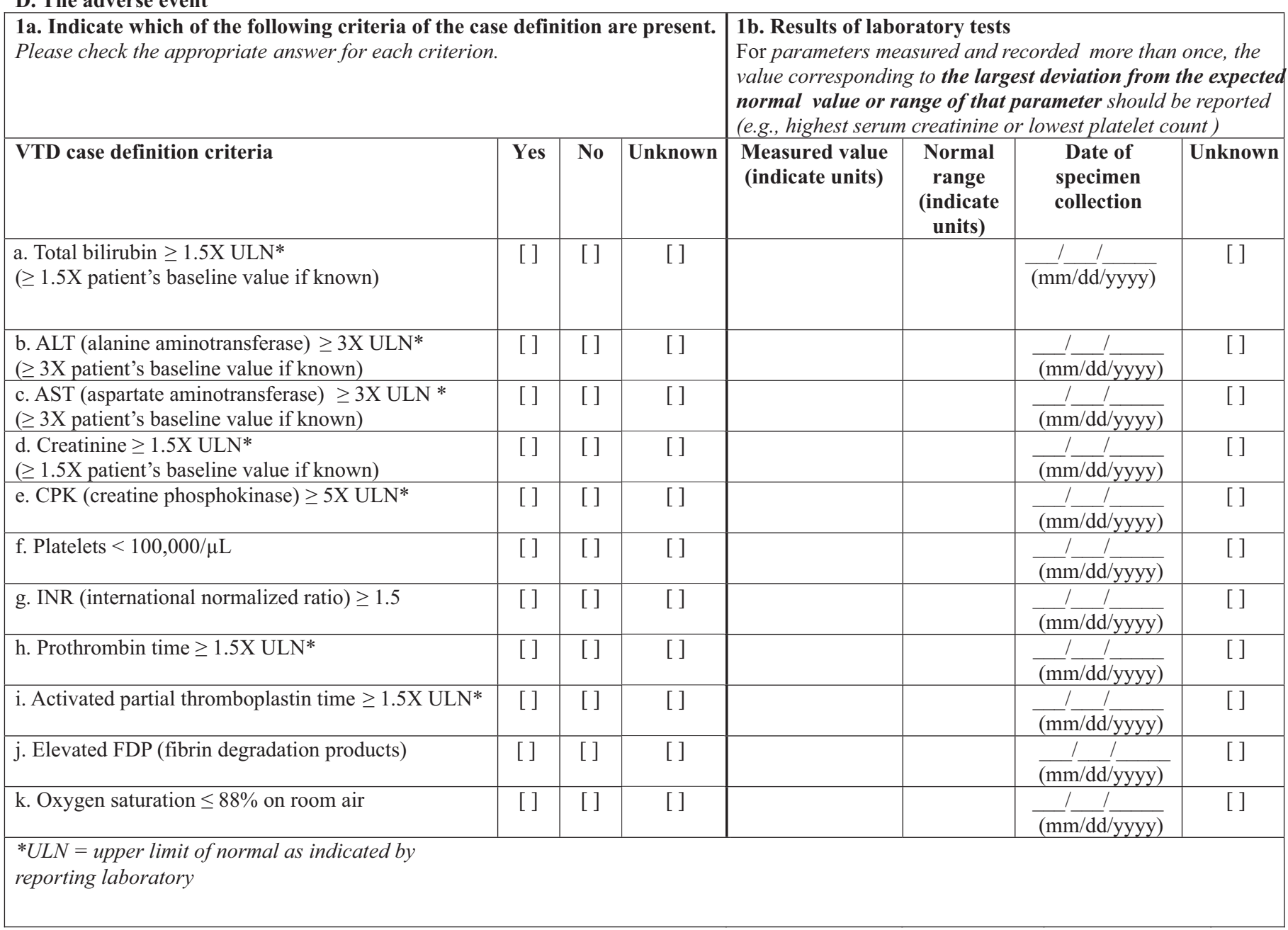




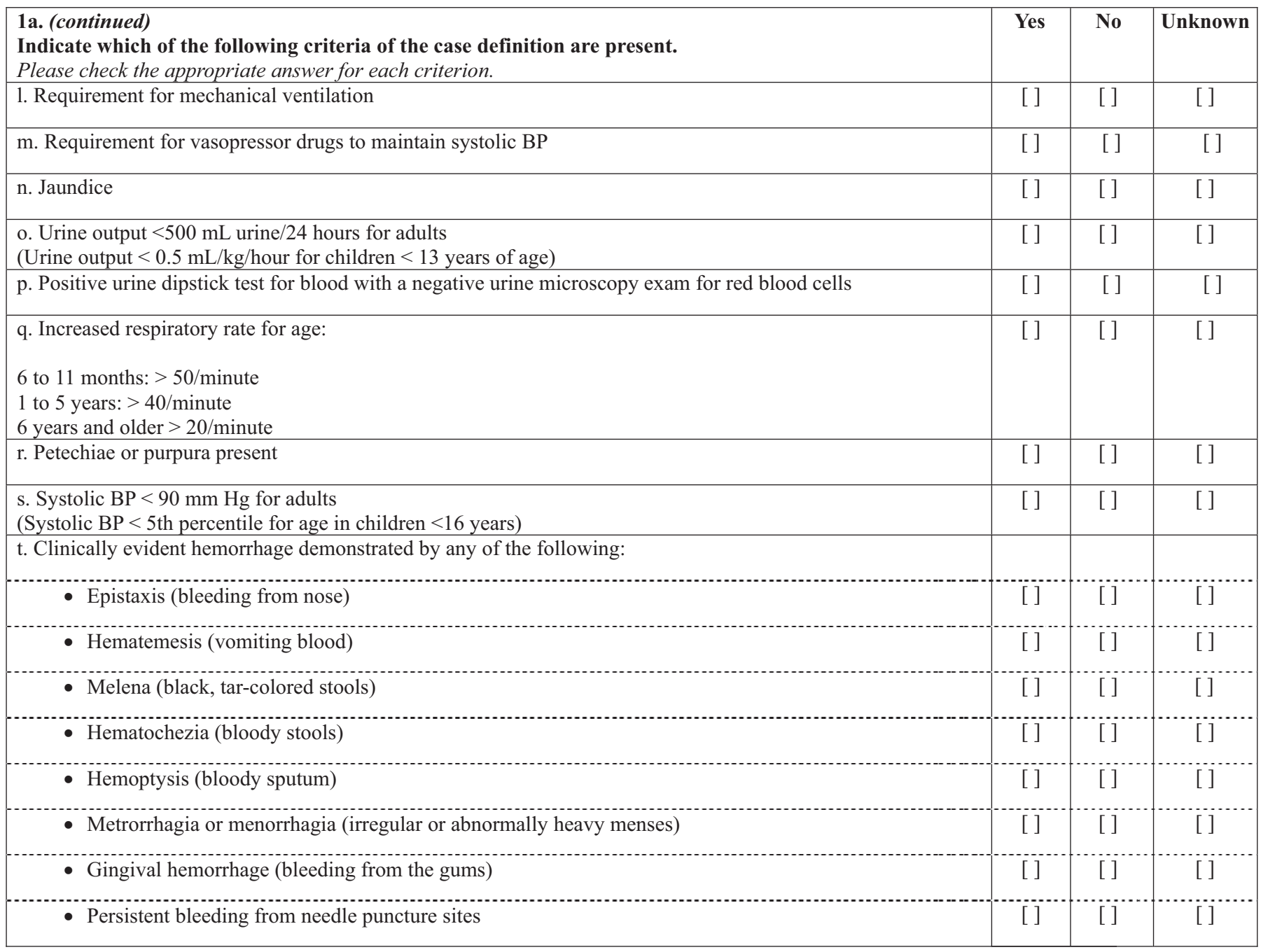




\section{Other clinical details of the event}

a. Results of other clinical tests:

b. Surgical findings and diagnoses:

c. Pathological findings and diagnoses:

d. Provide a detailed clinical description of the adverse event. When possible, provide detailed signs and symptoms (e.g., jaundice, hypoxia, hypotension, oliguria, discolored urine, tachypnea, petechiae, or hemorrhage) and the timing of each event relative to timing of vaccination (e.g., 2 days postvaccination).

\begin{tabular}{|c|c|c|c|}
\hline $\begin{array}{l}\text { e. Other than VTD, did the patient have any concurrent signs or symptoms or acute } \\
\text { diseases? }\end{array}$ & [] Yes & {[] $\mathrm{No}$} & ] Unknown \\
\hline
\end{tabular}

If YES, please list:

f. Locations where the patient received medical care for this event

\begin{tabular}{|l|l|}
\hline List the names and addresses of physicians or institutions providing medical care & \\
\hline & \\
\hline & \\
\hline & \\
\hline & \\
\hline
\end{tabular}




\begin{tabular}{|c|c|c|c|}
\hline 3. Date and time of milestones & Date & $\begin{array}{c}\text { Time (circle am } \\
\text { or } \mathrm{pm} \text { ) }\end{array}$ & \\
\hline $\begin{array}{l}\text { a. Onset of adverse event } \\
\text { (the date postimmunization when the first sign or } \\
\text { symptom suggestive of VTD occurred, per the vaccine } \\
\text { recipient's or family's account) }\end{array}$ & $\overline{(\mathrm{mm} / \mathrm{dd} / \mathrm{yyyy})}$ & $\mathrm{am} / \mathrm{pm}$ & [] Unknown \\
\hline $\begin{array}{l}\text { b. First observation } \\
\text { (earliest documentation in medical record of signs or } \\
\text { symptoms suggestive of VTD) }\end{array}$ & $\overline{(\mathrm{mm} / \mathrm{dd} / \mathrm{yyyy})}$ & $\mathrm{am} / \mathrm{pm}$ & [] Unknown \\
\hline $\begin{array}{l}\text { c. Hospitalization } \\
\text { (the earliest date of hospitalization for the adverse } \\
\text { event) }\end{array}$ & $\overline{(\mathrm{mm} / \mathrm{dd} / \mathrm{yyyy})}$ & $\mathrm{am} / \mathrm{pm}$ & [] Unknown \\
\hline $\begin{array}{l}\text { d. Diagnosis } \\
\text { (the date postimmunization when the adverse event met } \\
\text { the VTD case definition at any level) }\end{array}$ & $\overline{(\mathrm{mm} / \mathrm{dd} / \mathrm{yyyy})}$ & $\mathrm{am} / \mathrm{pm}$ & [] Unknown \\
\hline $\begin{array}{l}\text { e. End of episode } \\
\text { (the date when the adverse event no longer met the } \\
\text { VTD case definition) }\end{array}$ & $\overline{(\mathrm{mm} / \mathrm{dd} / \mathrm{yyyy})}$ & $\mathrm{am} / \mathrm{pm}$ & [ ] Unknown \\
\hline $\begin{array}{l}\text { f. Last observation } \\
\text { (the date of the last clinical evaluation of the patient } \\
\text { with VTD) }\end{array}$ & $\overline{(\mathrm{mm} / \mathrm{dd} / \mathrm{yyyy})}$ & $\mathrm{am} / \mathrm{pm}$ & [] Unknown \\
\hline
\end{tabular}

\begin{tabular}{|c|c|c|c|}
\hline \multicolumn{4}{|c|}{ 4. Document all treatments given for VTD } \\
\hline a. Hospitalization & [] Yes & [] No & [] Unknown \\
\hline b. Supplemental oxygen & [] Yes & [] No & [] Unknown \\
\hline c. Intravenous fluids & [] Yes & [] No & [] Unknown \\
\hline d. Vasopressor drugs & [] Yes & [] No & [] Unknown \\
\hline e. Mechanical ventilation & [] Yes & [] No & [] Unknown \\
\hline f. Hemodialysis & [] Yes & [] No & [] Unknown \\
\hline g. Corticosteroids & [] Yes & [] No & [ ] Unknown \\
\hline h. Antiviral drugs & [] Yes & [] No & [] Unknown \\
\hline i. Other medications and/or treatments & [] Yes & [] No & [] Unknown \\
\hline \multicolumn{4}{|c|}{ j. If other medications/treatments given, please list each here: } \\
\hline
\end{tabular}




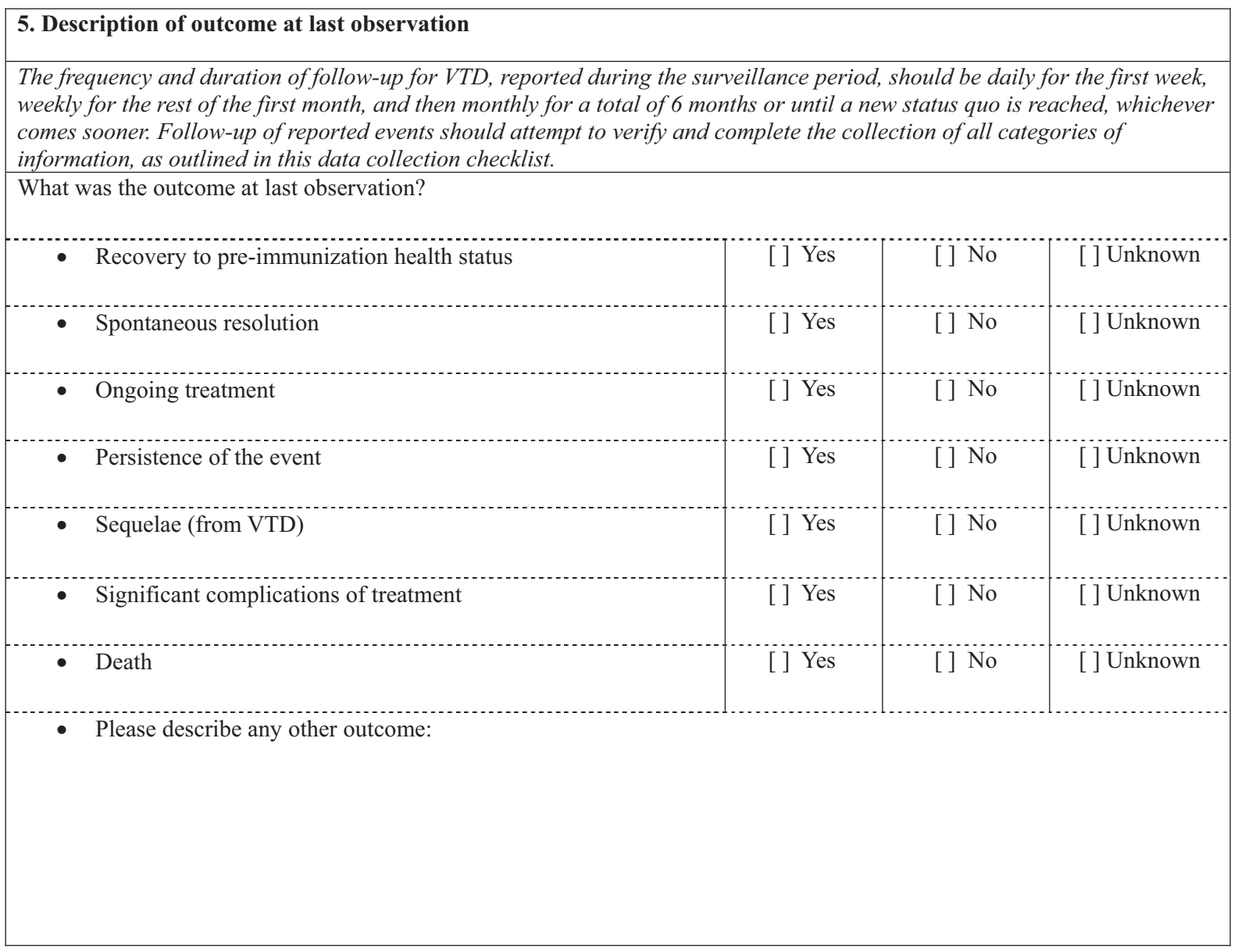

\section{E. Miscellaneous}

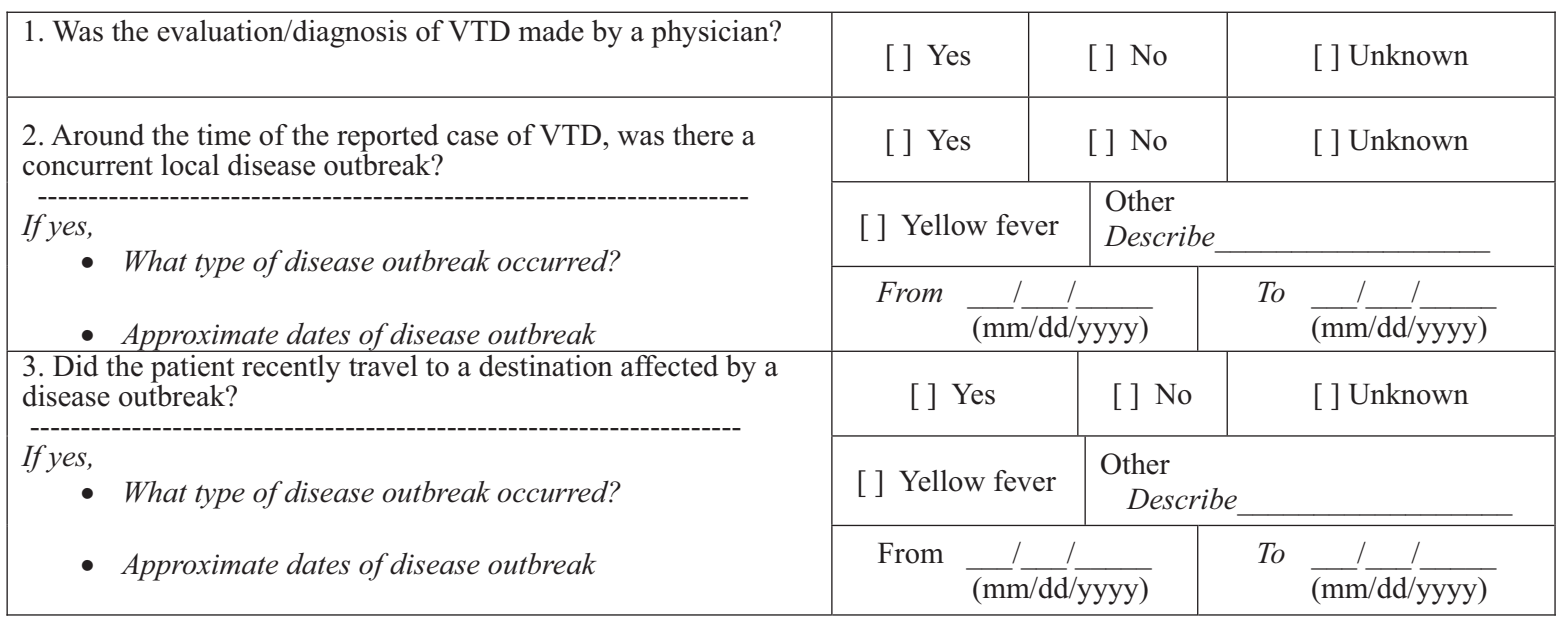


4. Please add any other comments or a clinical narrative that you think will add to the understanding of the clinical course or pathophysiology of this adverse event. A copy of the medical record relating to the event may be attached. 
B.2. Data collection checklist for 17D yellow fever (YF) vaccine causality assessment

For cases in which YF vaccine was administered and YF virus-specific testing performed

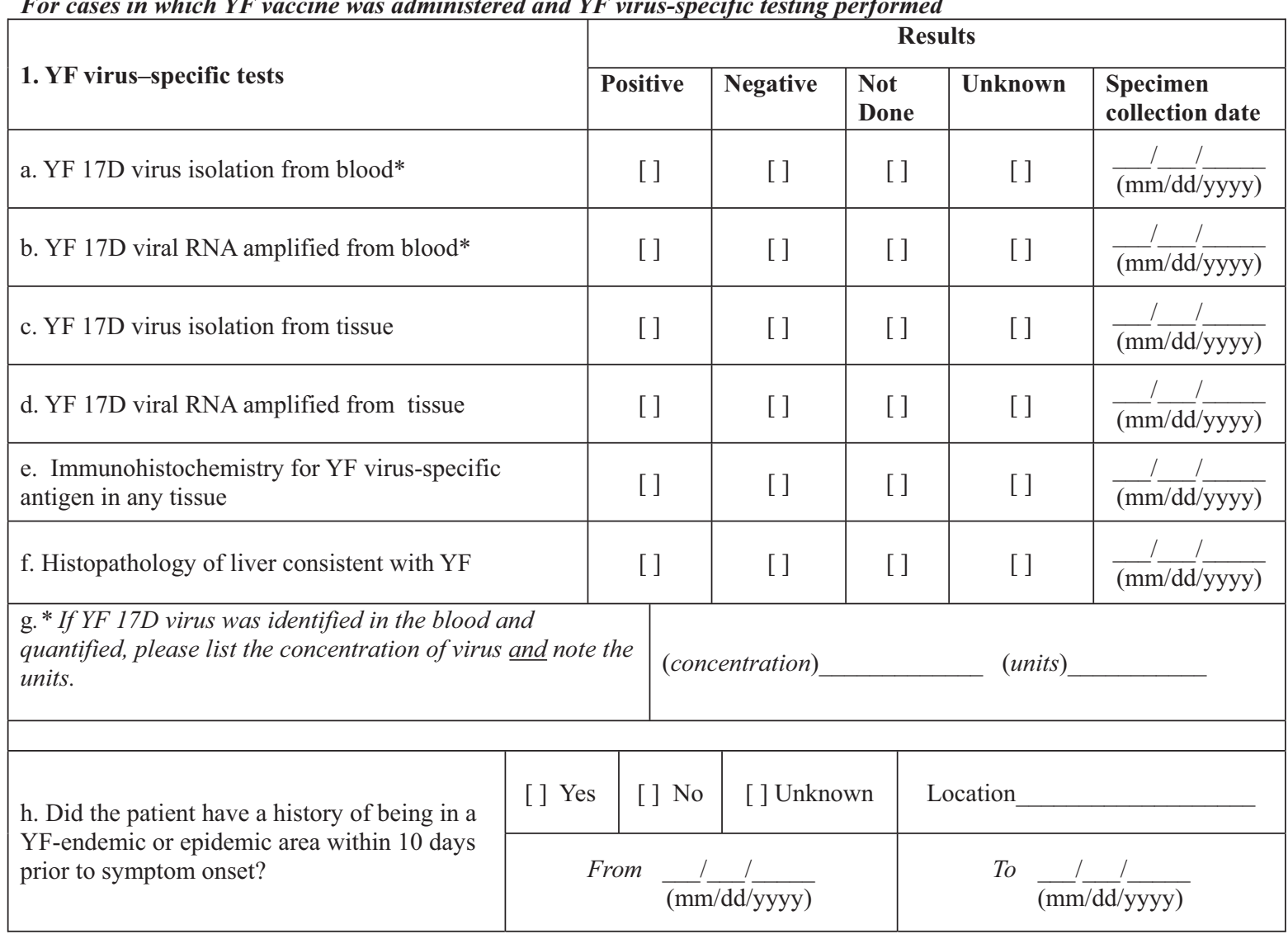

If YF virus-specific testing performed on tissue:

\begin{tabular}{|c|c|c|c|}
\hline \multicolumn{4}{|c|}{ 2. Organ-specific results of YF virus-specific testing } \\
\hline \multirow[t]{2}{*}{ Organ } & \multicolumn{3}{|c|}{ Tests performed } \\
\hline & YF 17D virus isolation & $\begin{array}{c}\text { YF 17D viral RNA } \\
\text { amplification }\end{array}$ & $\begin{array}{c}\text { Immunohistochemistry for } \\
\text { YF virus antigen }\end{array}$ \\
\hline a. Liver & []Pos []Neg [ ]Not done & []Pos []Neg [ ]Not done & []Pos []Neg [ ]Not done \\
\hline b. Kidney & []Pos []Neg [ ]Not done & [ ]Pos [ ]Neg [ ]Not done & []Pos [ ]Neg [ ]Not done \\
\hline c. Heart & []Pos []Neg [ ]Not done & [ ]Pos [ ]Neg [ ]Not done & [ ]Pos [ ]Neg [ ]Not done \\
\hline d. Lung & []Pos []Neg [ ]Not done & [ ]Pos [ ]Neg [ ]Not done & [ ]Pos [ ]Neg [ ]Not done \\
\hline e. Brain & []Pos []Neg [ ]Not done & [ ]Pos [ ]Neg [ ]Not done & [ ]Pos [ ]Neg [ ]Not done \\
\hline f. Other & []Pos []Neg [ ]Not done & [ ]Pos [ ]Neg [ ]Not done & [ ]Pos [ ]Neg [ ]Not done \\
\hline g. Other & [ ]Pos [ ]Neg [ ]Not done & [ ]Pos [ ]Neg [ ]Not done & []Pos [ ]Neg [ ]Not done \\
\hline
\end{tabular}

\section{References}

[1] Chan RC, Penney DJ, Little D, Carter IW, Roberts JA, Rawlinson WD. Hepatitis and death following vaccination with 17D-204 yellow fever vaccine. Lancet 2001;358(9276):121-2.

[2] Martin M, Tsai TF, Cropp B, Chang GJ, Holmes DA, Tseng J, et al. Fever and multisystem organ failure associated with 17D-204 yellow fever vaccination: a report of four cases. Lancet 2001;358(9276):98-104.

[3] Vasconcelos PF, Luna EJ, Galler R, Silva LJ, Coimbra TL, Barros VL, et al. Serious adverse events associated with yellow fever 17DD vaccine in Brazil: a report of two cases. Lancet 2001;358(9276):91-7.
[4] Troillet N, Laurencet F. Effects of yellow fever vaccination. Lancet 2001;358(9296):1908-9.

[5] Werfel U, Popp W. Effects of yellow fever vaccination. Lancet 2001;358(9296):1909.

[6] Adhiyaman V, Oke A, Cefai C. Effects of yellow fever vaccination. Lancet 2001;358(9296):1907-8.

[7] Centers for Disease Control and Prevention. Adverse events associated with 17D-derived yellow fever vaccination-United States, 2001-2002. MMWR 2002;51(44):989-93.

[8] Centers for Disease Control and Prevention. Yellow fever vaccine: recommendations of the Advisory Committee on Immunization Practices (ACIP). MMWR 2010;59(RR-7):1-27. 
[9] Struchiner CJ, Luz PM, Dourado I, Sato HK, Aguiar SG, Ribeiro JG, et al. Risk of fatal adverse events associated with 17DD yellow fever vaccine. Epidemiol Infect 2004;132(5):939-46.

[10] Gerasimon G, Lowry K. Rare case of fatal yellow fever vaccine-associated viscerotropic disease. South Med J 2005;98(6):653-6.

[11] Doblas A, Domingo C, Bae HG, Bohorquez CL, de Ory F, Niedrig M, et al. Yellow fever vaccine-associated viscerotropic disease and death in Spain. J Clin Virol 2006;36(2):156-8

[12] Whittembury A, Ramirez G, Hernandez H, Ropero AM, Waterman S, Ticona M, et al. Viscerotropic disease following yellow fever vaccination in Peru. Vaccine 2009;27(43):5974-81.

[13] Douce RW, Freire D, Tello B, Vasquez GA. A case of yellow fever vaccine-associated viscerotropic disease in Ecuador. Am J Trop Med Hyg 2010;82(4):740-2.

[14] Belsher JL, Gay P, Brinton M, DellaValla J, Ridenour R, Lanciotti R, et al. Fatal multiorgan failure due to yellow fever vaccine-associated viscerotropic disease. Vaccine 2007;25(50):8480-5.

[15] Khromava AY, Eidex RB, Weld LH, Kohl KS, Bradshaw RD, Chen RT, et al. Yellow fever vaccine: an updated assessment of advanced age as a risk factor for serious adverse events. Vaccine 2005;23(25):3256-63.

[16] Lindsey NP, Schroeder BA, Miller ER, Braun MM, Hinckley AF, Marano N et al. Adverse event reports following yellow fever vaccination. Vaccine 2008;26(48):6077-82.

[17] Kitchener S. Viscerotropic and neurotropic disease following vaccination with the 17D yellow fever vaccine, ARILVAX Vaccine $2004 \cdot 22(17-18): 2103-5$.

[18] Martins RM, Maia MLS, Santos EM, Cruz RLS, Santos PRG, Carvalho SMD, et al. Yellow fever post-marketing surveillance in Brazil. Procedia Vaccinol 2010;2:178-83.

[19] Barwick R. History of thymoma and yellow fever vaccination. Lancet 2004;364(9438):936.

[20] Monath T, Cetron MS, Teuwen DE. Yellow fever vaccine. In: Plotkin SA, Orenstein WA, Offit PA, editors. Vaccines. 5th ed. Philadelphia, PA: Saunders Elsevier; 2008. p. 959-1055.

[21] World Health Organization. Detection and investigation of serious adverse events following yellow fever vaccination: guidance from an informal consultation of experts, 18-19 November 2008, Geneva, Switzerland 2010. Available on the world wide web: http://whqlibdoc.who.int/ hq/2010/WHO_HSE_GAR_ERI_2010.2_eng.pdf (last accessed March 23, 2012).

[22] World Health Organization. Surveillance of adverse events following immunization against yellow fever: field guide for staff at the central, intermediate and peripheral level, 2010. Available on the world wide web: http://whqlibdoc. who.int/hq/2010/WHO_HSE_GAR_ERI_2010.1_eng.pdf (last accessed March 23, 2012).

[23] World Health Organization. Yellow fever surveillance and outbreak response: revision of case definitions, October 2010. Wkly Epidemiol Rec 2010;85(47):465-72.

[24] Kohl KS, Gidudu J, Bonhoeffer J, Braun MM, Buettcher M, Chen RT, et al. The development of standardized case definitions and guidelines for adverse events following immunization. Vaccine 2007;25(31):5671-4.

[25] Schrauder A, Henke-Gendo C, Seidemann K, Sasse M, Cario G, Moericke A, et al. Varicella vaccination in a child with acute lymphoblastic leukaemia. Lancet 2007;369(9568):1232.

[26] Ghaffar F, Carrick K, Rogers BB, Margraf LR, Krisher K, Ramilo O. Disseminated infection with varicella-zoster virus vaccine strain presenting as hepatitis in a child with adenosine deaminase deficiency. Pediatr Infect Dis 2000;19(8):764-6.

[27] Rasch DK, Wells O, Fowlkes J. Fatal disseminated infection due to poliovirus type 2 vaccine. Am J Dis Child 1986;140(12):1211-2.

[28] Jouanguy E, Altare F, Lamhamedi S, Revy P, Emile JF, Newport M, et al. Interferon-gamma-receptor deficiency in an infant with fatal bacille CalmetteGuerin infection. N Engl J Med 1996;335(26):1956-61.

[29] Guy B, Guirakhoo F, Barban V, Higgs S, Monath TP, Lang J. Preclinical and clinical development of YFV 17D-based chimeric vaccines against dengue, West Nile and Japanese encephalitis viruses. Vaccine 2010;28(3):632-49.

[30] Monath TP. Yellow fever: an update. Lancet Infect Dis 2001;1(1):11-20.

[31] Benichou C, Solal Celigny P. Standardization of definitions and criteria for causality assessment of adverse drug reactions. Drug-induced blood cytopenias: report of an international consensus meeting. Nouv Rev Fr Hematol 1991;33(3):257-62.

[32] Wise RP, Bonhoeffer J, Beeler J, Donato H, Downie P, Matthews D, et al. Thrombocytopenia: case definition and guidelines for collection, analysis, and presentation of immunization safety data. Vaccine 2007;25(31): 5717-24.

[33] Huerta-Alardin AL, Varon J, Marik PE. Bench-to-bedside review: rhabdomyolysis-an overview for clinicians. Crit Care 2005;9(2):158-69.

[34] Warren JD, Blumbergs PC, Thompson PD. Rhabdomyolysis: a review. Muscle Nerve 2002;25(3):332-47.

[35] Bagley WH, Yang $\mathrm{H}$, Shah $\mathrm{KH}$. Rhabdomyolysis. Intern Emerg Med 2007;2(3):210-8.

[36] Sauret JM, Marinides G, Wang GK. Rhabdomyolysis. Am Fam Physician 2002;65(5):907-12.

[37] Craig S. Rhabdomyolysis in emergency medicine. eMedicine: updated September 21,2011. Available on the world wide web: http://emedicine. medscape.com/article/827738-overview (last accessed March 23, 2012).
[38] Muscal E. Morales de Guzman M. Pediatric rhabdomyolysis. eMedicne: updated April 27,2010. Available on the world wide web: http://emedicine.medscape.com/article/1007814-diagnosis (last accessed March 23, 2012)

[39] Pratt DS, Kaplan MM. Jaundice. In: Fauci AS, Kasper DL, Longo DL, Braunwald E, Hauser SL, Jameson JL, Loscalzo J, editors. Harrison's Principles of Internal Medicine. 17th ed. New York, NY: McGraw-Hill; 2008. p. 261-6.

[40] King CH, Keating CE, Muruka JF, Ouma JH, Houser H, Siongok TK, et al. Urinary tract morbidity in schistosomiasis haematobia: associations with age and intensity of infection in an endemic area of Coast Province, Kenya. Am J Trop Med Hyg 1988;39(4):361-8.

[41] Traore M, Traore HA, Kardorff R, Diarra A, Landoure A, Vester U, et al. The public health significance of urinary schistosomiasis as a cause of morbidity in two districts in Mali. Am J Trop Med Hyg 1998;59(3):407-13.

[42] Grossfeld GD, Litwin MS, Wolf JS, Hricak H, Shuler CL, Agerter DC, et al Evaluation of asymptomatic microscopic hematuria in adults: the American Urological Association best practice policy-part I: definition, detection, prevalence, and etiology. Urology 2001;57(4):599-603.

[43] Mazza Nascimento M, Riella MC. Raising awareness of chronic kidney disease in a Brazilian urban population. Braz J Med Biol Res 2009;42(8):750-5.

[44] Tsaras G, Owusu-Ansah A, Boateng FO, Amoateng-Adjepong Y. Complications associated with sickle cell trait: a brief narrative review. Am J Med 2009;122(6):507-12.

[45] International Conference on Harmonisation of Technical Requirements for Registration of Pharmaceuticals for Human Use (ICH). Guidelines for Clinical Safety Assesment (E2a-e). Available on the world wide web: http://www.ich.org/fileadmin/Public_Web_Site/ICH_Products/Guidelines/ Efficacy/E2A/Step4/E2A_Guideline.pdf (last accessed March 23, 2012).

[46] Council for International Organizations of Medical Sciences (CIOMS). Suspect adverse reaction report form. Available on the world wide web: http://www.cioms.ch/form/frame_form.htm (last accessed March 23,2012).

[47] The CONSORT 2010 Statement: Updated guidelines for reporting parallel group randomized trials. Ann Intern Med 2010; 152(11):726-32. Available on the world wide web: http://www.consort-statement.org/consort-statement/ (last accessed March 23, 2012).

[48] Moher D, Cook DJ, Eastwood S, Olkin I, Rennie D, Stroup DF. Improving the quality of reports of meta-analyses of randomised controlled trials: the QUOROM statement. Quality of reporting of meta-analyses. Lance 1999;354(9193):1896-900.

[49] Des Jarlais DC, Lyles C, Crepaz N. Improving the reporting quality of nonrandomized evaluations of behavioral and public health interventions: the TREND statement. Am J Public Health 2004;94(3):361-6.

[50] von Elm E, Altman DG, Egger M, Pocock SJ, Gotzsche PC, Vandenbroucke JP. The strengthening the reporting of observational studies in epidemiology (STROBE) statement: guidelines for reporting observational studies. Ann Intern Med 2007;147(8):573-7.

[51] Stroup DF, Berlin JA, Morton SC, Olkin I, Williamson GD, Rennie D, et al. Metaanalysis of observational studies in epidemiology: a proposal for reporting Meta-analysis Of Observational Studies in Epidemiology (MOOSE) group. JAMA 2000;283(15):2008-12.

[52] Reinhardt B, Jaspert R, Niedrig M, Kostner C, L'Age-Stehr J. Development of viremia and humoral and cellular parameters of immune activation after vaccination with yellow fever virus strain 17D: a model of human flavivirus infection. J Med Virol 1998;56(2):159-67.

[53] Monath TP, McCarthy K, Bedford P, Johnson CT, Nichols R, Yoksan S, et al. Clinical proof of principle for ChimeriVax: recombinant live, attenuated vaccines against flavivirus infections. Vaccine 2002;20(7-8):1004-18.

[54] Monath TP, Guirakhoo F, Nichols R, Yoksan S, Schrader R, Murphy C, et al. Chimeric live, attenuated vaccine against Japanese encephalitis (ChimeriVaxJE): phase 2 clinical trials for safety and immunogenicity, effect of vaccine dose and schedule, and memory response to challenge with inactivated Japanese encephalitis antigen. J Infect Dis 2003;188(8):1213-30.

[55] Wheelock EF, Sibley WA. Circulating virus, interferon and antibody after vaccination with the 17-D strain of yellow-fever virus. N Engl J Med 1965;273:194-8.

[56] Pulendran B, Miller J, Querec TD, Akondy R, Moseley N, Laur O, et al. Case of yellow fever vaccine-associated viscerotropic disease with prolonged viremia, robust adaptive immune responses, and polymorphisms in CCR5 and RANTES genes. J Infect Dis 2008;198(4):500-7.

[57] Roukens AH, Soonawala D, Joosten SA, de Visser AW, Jiang X, Dirksen K, et al. Elderly subjects have a delayed antibody response and prolonged viraemia following yellow fever vaccination: a prospective controlled cohort study. PloS One 2011;6(12):e27753.

[58] Monath TP, Liu J, Kanesa-Thasan N, Myers GA, Nichols R, Deary A, et al. A live, attenuated recombinant West Nile virus vaccine. Proc Natl Acad Sci USA 2006;103(17):6694-9.

[59] Centers for Disease Control and Prevention. Transmission of yellow fever vaccine virus through breast-feeding - Brazil, 2009. MMWR 2010;59(5):130-2.

[60] Traiber C, Coelho-Amaral P, Ritter VR, Winge A. Infant meningoencephalitis caused by yellow fever vaccine virus transmitted via breastmilk. J Pediatr (Rio J) $2011 ; 87(3): 269-72$.

[61] Kuhn S, Twele-Montecinos L, MacDonald J, Webster P, Law B. Case report: probable transmission of vaccine strain of yellow fever virus to an infant via breast milk. CMAJ 2011;183(4):E243-5.

[62] Centers for Disease Control and Prevention. Transfusion-related transmission of yellow fever vaccine virus-California, 2009. MMWR 2010;59(2):34-7. 